\title{
Dietary fibre-rich oat-based products affect serum lipids, microbiota, formation of short-chain fatty acids and steroids in rats
}

\author{
Barbora Drzikova ${ }^{1}$, Gerhard Dongowski $^{1}$ and Erich Gebhardt ${ }^{2}$ \\ ${ }^{1}$ German Institute of Human Nutrition Potsdam-Rehbruecke, Research Group Food Chemistry and Preventive Nutrition, D-14558 \\ Nuthetal, Germany \\ ${ }^{2}$ Institute of Nutritional and Environmental Research, D-14558 Nuthetal, Germany
}

(Received 23 February 2005 - Revised 14 June 2005 - Accepted 14 July 2005)

\begin{abstract}
Wistar rats (ten per group) were fed either an oat-free control diet or a dietary fibre-rich test diet containing $500 \mathrm{~g}$ oat-based products/kg for 6 weeks. The oat-based products, containing 4-128 g/kg resistant starch, 30-92 g/kg $\beta$-glucan and 122-304 g/kg total dietary fibre, were oat flour extrudate, flour/Novelose (commercial resistant starch) extrudate $(80: 20 \mathrm{w} / \mathrm{w})$, oat bran, bran/Novelose extrudate (80:20 w/w) and autoclaved oat flour. Serum total cholesterol decreased in the groups fed flour, flour/Novelose and bran/Novelose $(P<0.05)$. In most of the test groups, count numbers of bifidobacteria were higher $(P<0.001)$ and of coliforms were lower $(P<0.05)$. The mass of the caecum walls and contents was greater in groups fed Novelose- and bran-containing diets $(P<0 \cdot 005)$. In all the test groups, $\mathrm{pH}$ values were lower in the intestinal contents $(P<0 \cdot 001)$, and caecal concentrations of acetate $(P<0 \cdot 001)$, propionate $(P<0.05)$, butyrate $(P<0.005)$ and total SCFA $(P<0.001)$ were higher. The lowest concentrations of steroids were found in rats fed the autoclaved flour. In the other test groups, more bile acids appeared in the caecal $(P<0.001)$ and colonic contents $(P<0 \cdot 005)$, as well as in the faeces, at week 6 $(P<0.001)$. The highest bile acid excretion was found after feeding bran-containing diets. In the intestinal contents of all the test groups, more primary bile acids $(P<0.001)$ appeared than in the control group. The excretion of steroids increased within the experimental period. Using extrusion technology, dietary fibre-rich oat-based products, which have beneficial physiological effects in rats, can be produced. Oat flour and bran are excellent sources for the preparation of directly edible oat products. Their nutritional properties can be further improved by the addition of resistant starch.
\end{abstract}

Oat: Physiological effect: Short-chain fatty acid: Steroid: Rat

Oat (Avena sativa L.) products are well accepted in human nutrition. They contain relatively high concentrations of protein, lipids, vitamins, antioxidants, phenolic compounds and minerals (Hampshire, 1998; Emmons \& Peterson, 1999; Zadernowski et al. 1999; Peterson, 2001; Panfili et al. 2003). Furthermore, oat is an excellent source of different dietary fibre (DF) types, such as mixed-linked $(1 \rightarrow 3),(1 \rightarrow 4)$ - $\beta$-D-glucan (here referred to as $\beta$-glucan), arabinoxylans and cellulose. DF are essential components of human nutrition. A high intake of DF is positively related to several preventive medical and nutritional effects (Spiller, 2001). However, the daily intake of DF is below the recommended concentration of at least $30 \mathrm{~g}$ for adults in most of the industrialised countries (Cummings \& Frølich, 1993; Deutsche Gesellschaft für Ernährung, 2004).

Among the DF components of oat, $\beta$-glucan plays an important role because of its viscosity and functional properties in the gastrointestinal tract (Doublier \& Wood, 1995; Tejinder et al. 2000; Mälkki \& Virtanen, 2001; Dongowski et al. 2005). Several effects of $\beta$-glucan in the upper intestinal tract are under discussion. It may thus lower the postprandial blood glucose and insulin responses in normal individuals (Braaten et al. 1991). Furthermore, $\beta$-glucan has cholesterol-lowering effects in hypercholesterolaemic humans and animals (Kahlon et al. 1993;
Braaten et al. 1994; Hecker et al. 1998; Kalra \& Jood, 2001; Kerckhoffs et al. 2002; Delaney et al. 2003b). Interactions between $\beta$-glucan and bile acids (BA) in the small intestine are the precondition for the greater excretion of BA. A higher excretion of BA causes their increased synthesis from cholesterol, as shown during the consumption of $\beta$-glucan from oat bran (Andersson et al. 2002). This effect is connected with a lowering of blood cholesterol level in the presence of $\beta$-glucan-rich diets (Zhang et al. 1992).

$\beta$-Glucan is practically completely fermented in the caecum and colon by the microflora. Major fermentation products are SCFA, which are important for a healthy colonic mucosa (Daniel et al. 1997; Topping \& Clifton, 2001).

In oat products such as bran, the native three-dimensional DFrich cell wall architecture may be partly preserved during passage through the intestinal tract. It is well known that cereal bran significantly accelerates transit time and increases daily faecal weight in humans (Lupton et al. 1993).

Another DF component present in certain cereal (starchy) products is so-called resistant starch (RS). RS is defined as the starch, or starch degradation products, that is not absorbed in the small intestine of healthy individuals. It is a major substrate for fermentation by intestinal bacteria and is a good source of butyrate (Asp 
et al. 1996; Brouns et al. 2002). There are two principal ways to increase the proportion of RS in cereal products: the addition of commercially available RS preparations or special treatments (e.g. the controlled heating/cooling) of starch-containing materials. It was thus possible to generate RS in barley products (Huth et al. 2000) but not in oat flour (Gebhardt et al. 2004) by extrusion.

Food-processing such as extrusion can influence the digestibility of starch in cereal products (Bornet, 1993). There is scant information on the influence of the composition of extruded products on their physiological effects. Chang et al. (2002) reported on the hypocholesterolaemic properties of extrudates prepared from mixtures of cassava starch and Novelose or oat fibre. However, the proportions of the components in the extrudates were not given.

The objective of the present study was to evaluate the physiological and nutritional effects of DF-rich oat-based products (e.g. extrudates) in rats. The oat-based products tested differed in their contents of individual DF such as $\beta$-glucan and RS, as well as of soluble and insoluble DF. A higher consumption of such oat products should improve the intake of DF and other essential nutrients. Oats are a cereal with an important nutritional value but are used as food at a relatively low level in most countries. Our hypothesis was that the composition and pre-treatment of oatbased products would be important for the direct or indirect physiological effects of oat products in the intestinal tract.

\section{Materials and methods}

\section{Source materials and oat products}

Oat flour was prepared from commercial oat kernels by milling. Oat bran was obtained from Peter Kölln Köllnflockenwerke (Elmshorn, Germany). Novelose 330 is a commercial RS product from National Starch \& Chemical (Hamburg, Germany).

The oat-based extrudates oat flour (product F), oat flour/Novelose (product FN; 80:20 w/w) and oat bran/Novelose (product BN; 80:20 w/w) were prepared in the twin-screw extruder ERMAFA DS $6 \cdot 0$ (ERMAFA Kunststofftechnik, Chemnitz, Germany) using the following conditions: moisture content $25 \%$, mass temperature $150^{\circ} \mathrm{C}$, screw speed $200 \mathrm{rpm}$ and dosage $100 \mathrm{~kg} / \mathrm{h}$. Oat product B consisted of untreated oat bran. Furthermore, oat flour was treated twice for $60 \mathrm{~min}$ at $140^{\circ} \mathrm{C}$ and at a moisture content of $25 \%$ in the Sanoclav autoclave (Adolf Wolf, Bad Überkingen-Hausen, Germany) (product F\#).

\section{Experimental diets}

The experimental diets were prepared as pellets in the German Institute of Human Nutrition, Potsdam-Rehbruecke (Table 1). The oat-based test diets contained $500 \mathrm{~g} / \mathrm{kg}$ oat products and only $130 \mathrm{~g} / \mathrm{kg}$ wheat starch (partial replacement of the wheat starch used in the control diet).

\section{Rat experiment}

Young male Wistar rats (Tierzucht Schönwalde GmbH, Schönwalde, Germany) were housed individually in temperature- and humidity-controlled cages $\left(22^{\circ} \mathrm{C}\right.$ and $\left.55 \%\right)$ on a normal $12 \mathrm{~h}$ light/dark cycle. During the adaptation period, all rats were fed the control diet for $7 \mathrm{~d}$ after arrival (week 0 ). Then they were randomly divided into six groups of ten rats each and fed the control diet or the oat-based test diets for 6 weeks. The rats had free access to food and water during the experiment.

Growth of the rats and food and water intake were determined weekly. To determine the steroid levels, faeces were collected completely for $24 \mathrm{~h}$ at weeks $0,2,4$ and 6 . Blood samples were taken from eye plexus of ether-anaesthetised rats, after a $16 \mathrm{~h}$ fast, for analysis of serum lipids at weeks 0 and 6 . After 6 weeks of the diet, rats were killed, and selected organs (e.g. ileum, caecum, colon) and the contents of ileum, caecum and colon were prepared for analysis. The colon was divided into the proximal and the distal part. SCFA, steroids, DM, pH values and RS were analysed in the intestinal contents. The microbial counts were determined at the end of the experiment in fresh faecal samples collected directly from the anus.

The rat experiment was carried out in the Max-Rubner-Laboratory of the German Institute of Human Nutrition, PotsdamRehbruecke in 2003. The experimental protocol was performed according to international and national guidelines. All treatments and diets were formally approved by the Animal Welfare Committee of the State Brandenburg (Ministry for Agriculture,

Table 1. Composition of the control diet and the oat-based diets $(\mathrm{g} / \mathrm{kg})$

\begin{tabular}{lcrrrrr}
\hline Diet & Control diet & Diet F & Diet FN & Diet B & Diet BN & Diet F\# \\
\hline Casein* $^{*}$ & 200 & 200 & 200 & 200 & 200 & 200 \\
Wheat starch† & 630 & 130 & 130 & 130 & 130 & 130 \\
Oat-based product & 0 & 500 & 500 & 500 & 500 & 500 \\
Sunflower-seed oilł & 50 & 50 & 50 & 50 & 50 & 50 \\
Microcrystalline cellulose§ & 50 & 50 & 50 & 50 & 50 & 50 \\
Mineral mixturell & 50 & 50 & 50 & 50 & 50 & 50 \\
Vitamin mixture & 20 & 20 & 20 & 20 & 20 & 20 \\
\hline
\end{tabular}

F, oat flour; FN, oat flour/Novelose; B, oat bran; BN, oat bran/Novelose; F\#, oat flour (autoclaved).

${ }^{*}$ Casein, edible (Bayerische Milchindustrie e.G., Landshut, Germany).

† Hermann Kröner GmbH Co. KG, Ibbenbüren, Germany.

$\ddagger$ Łrölio Europe GmbH/ÖImühle GmbH + Co., Hamm, Germany.

$\S$ Vivapur (Heweten 20) (Rettenmaier \& Söhne GmbH + Co., Ellwangen-Holzmühle, Germany).

II Altromin GmbH, Lage, Germany. The composition of the mineral mixture was (mg/kg diet): Ca, 7300; P, 4900; Na, 2000;

$\mathrm{Mg}, 450 ; \mathrm{K}, 6000 ; \mathrm{S}, 530 ; \mathrm{Cl}$, 3200; Fe, 150; Mn, 90; Zn, 20; Cu, 4; I, 0.4; Mo, 0.2; F, 4; Se, 0.2; Co, 0.1.

ๆ Altromin $\mathrm{GmbH}$, Lage, Germany. The composition of the vitamin mixture was (per kg diet): vitamin $\mathrm{A}, 15000 \mathrm{IE}$; vitamin $\mathrm{D}_{3}$,

$500 \mathrm{IU}$; vitamin $\mathrm{E}, 150 \mathrm{mg}$; vitamin $\mathrm{K}_{3}, 10 \mathrm{mg}$; vitamin $\mathrm{B}_{1}, 20 \mathrm{mg}$; vitamin $\mathrm{B}_{2}, 20 \mathrm{mg}$; vitamin $\mathrm{B}_{6}, 15 \mathrm{mg}$; vitamin $B_{12}$, $0.03 \mathrm{mg}$; niacin, $50 \mathrm{mg}$; pantothenic acid, $50 \mathrm{mg}$; folic acid, $10 \mathrm{mg}$; biotin, $0.2 \mathrm{mg}$; choline chloride, $1000 \mathrm{mg}$; $p$-aminobenzoic acid, $100 \mathrm{mg}$; inositol, $100 \mathrm{mg}$; vitamin C, $20 \mathrm{mg}$; methionine, $3500 \mathrm{mg}$. 
Environmental Protection and Regional Planning), Germany (permissions 32/48-3560-0/3).

\section{Analytical methods}

Insoluble and soluble DF fractions were analysed by the enzymatic-gravimetric Association of Official Analytical Chemists method (Prosky et al. 1988). Non-digestible oligosaccharides were estimated in the supernatant after coagulation of the soluble DF fraction with ethanol using HPLC with refractive index detection. RS was measured by a modified Englyst-method (Englyst et al. 1992) after hydrolysis of the digestible starch and extraction of the hydrolysis products with $80 \%$ ethanol v/v. The RS was dissolved in $1 \mathrm{M}-\mathrm{NaOH}$, hydrolysed with amyloglucosidase and determined enzymatically as released glucose. The total DF content was calculated as the sum of soluble and insoluble DF, nondigestible oligosaccharides and RS.

Total fat was determined by the Weibull-Stoldt method. Protein was estimated by a modified Kjeldahl method $(\mathrm{N} \times 6 \cdot 25)$. The total starch content was determined enzymatically using amyloglucosidase and the Boehringer glucose kit after extraction in 1 $\mathrm{M}-\mathrm{NaOH}$. The glucose released was analysed with the hexokinase/ glucose-6-phosphate dehydrogenase kit from Boehringer (Mannheim, Germany).

For the determination of $\beta$-glucan, sample material was suspended in phosphate buffer $(\mathrm{pH} 6.5)$ and mixed for $5 \mathrm{~min}$ at $100^{\circ} \mathrm{C}$. The diluted suspension was hydrolysed with lichenase (Megazyme International, Bray, Ireland) for $60 \mathrm{~min}$ at $40^{\circ} \mathrm{C}$ (McCleary \& Mugford, 1997). After dilution and centrifugation $(10 \mathrm{~min}$ at $1500 \mathrm{~g}$ ), a part of the supernatant was incubated with $\beta$-glucosidase (Megazyme) in acetate buffer at $\mathrm{pH} 4.5$ and $40^{\circ} \mathrm{C}$ for $15 \mathrm{~min}$. The glucose liberated was determined enzymatically.

Water uptake of the oat-based products was determined using the capillary suction method (Arrigoni et al. 1987) at $20^{\circ} \mathrm{C}$ for 15 min and was expressed as $\mathrm{g} \mathrm{H}_{2} \mathrm{O} / \mathrm{g}$ substance.

Before determining the acid extract viscosity in the Ubbelohde viscometer (at $25.0^{\circ} \mathrm{C}$ ), $50 \mathrm{~g}$ of the oat-based products were extracted with $500 \mathrm{ml} 0.2 \mathrm{M}-\mathrm{KCl} / \mathrm{HCl}$ at $\mathrm{pH} 1.5$ and $40^{\circ} \mathrm{C}$ for $2 \mathrm{~h}$ (Huth et al. 2000). The acid extract viscosity is given as relative viscosity $\left(\eta_{\text {rel }}=\eta / \eta_{0}\right.$, where $\eta$ is the viscosity of the extract and $\eta_{0}$ is that of the solvent).

To evaluate the molecular weight, $\beta$-glucan was extracted from the oat-based products using a modified method of Westerlund et al. (1993) by treatment with Termamyl 120L (Novo Nordisk A/S, Copenhagen, Denmark), pancreatin (Merck, Darmstadt, Germany) and a purification procedure (Dongowski et al. 2005). The intrinsic viscosity [ $\eta]$ was estimated at $25 \cdot 0{ }^{\circ} \mathrm{C}$ in an Ubbelohde viscometer (Schott Instruments $\mathrm{GmbH}$, Mainz, Germany). The $\beta$-glucan preparations were dissolved in water and then centrifuged for $10 \mathrm{~min}$ at $2000 \mathrm{~g}$. Relative viscosity was determined on the basis of flow times at different concentrations. The intrinsic viscosity $[\eta]$ was determined by extrapolating the calculated specific viscosity $\left(\eta_{\mathrm{sp}}=\eta_{\mathrm{rel}}-1\right)$ against the concentration of $\beta$-glucan using the Huggins equation. The average molecular weight $\left(\mathrm{M}_{\mathrm{w}}\right)$ was calculated using the Mark-Houwink equation $[\eta]=k \times \mathrm{M}_{\mathrm{w}}{ }^{a}$, where the factor $k$ and the exponent $a$ are dependent on the nature of the macromolecules and the solvent. In line with Vårum et al. (1991), $k=0.00067$ and $a=0.75$ were used for calculations.

Triacylglycerols, total cholesterol and HDL- and LDL-cholesterol were measured enzymatically in serum using commercial kits (Olympus Diagnostica GmbH, Hamburg, Germany). SCFA in the caecal contents were analysed by gas chromatography using a modified method of Brighenti (1997) as previously described (Dongowski et al. 2002).

The microbial counts were determined as described by Sembries et al. (2003). Approximately $0 \cdot 2 \mathrm{~g}$ fresh collected faeces was immediately placed into pre-weighed tubes and diluted with prereduced buffered peptone water. In duplicate, $0.05 \mathrm{ml}$ of each dilution was plated on non-selective and selective media. Columbia blood agar (BioMérieux, Nurtingen, Germany), Endo agar (BioMérieux) and Rogosa agar (Fluka, Taufkirchen, Germany) were incubated aerobically at $37^{\circ} \mathrm{C}$ to determine the total aerobes (for $48 \mathrm{~h}$ ), coliform bacteria (for $24 \mathrm{~h}$ ) and aerobic lactobacilli (for 48 h), respectively. Numbers of total anaerobes, Bacteroides and Bifidobacterium sp. were determined after $48 \mathrm{~h}$ anaerobic incubation of Columbia blood agar, Columbia blood agar supplemented with neomycin $(0 \cdot 1 \mathrm{~g} / \mathrm{l}$; Fluka) and sodium deoxycholate $(0 \cdot 2 \mathrm{~g} / \mathrm{l}$; Fluka), and Haenel/Müller-Beuthow medium. The composition of this medium was (g/l): peptone (10), yeast extract (7), $\mathrm{NaCl}$ (3), $\mathrm{Na}_{2} \mathrm{HPO}_{4}$ (2), agar (10), cystin (0.5), cystein (0.5), sodiumazide $(0 \cdot 1)$, bromocresol green (0.0125), neutral red (0.00 025), $2.5 \mathrm{ml}$ saline B (40 g/l $\mathrm{MgSO}_{4} .7 \mathrm{H}_{2} \mathrm{O}, 2 \mathrm{~g} / \mathrm{FeSO}_{4} .7 \mathrm{H}_{2} \mathrm{O}, 2 \mathrm{~g} / \mathrm{l} \mathrm{NaCl}$, $2.35 \mathrm{~g} / \mathrm{l} \mathrm{MnSO}_{4} .2 \mathrm{H}_{2} \mathrm{O}$ ), respectively. Faecal microbial counts were expressed as $\log _{10}$ colony-forming units/g.

The procedures for extraction and purification from freezedried intestinal contents and faecal materials, as well as the analysis of BA by HPLC using pre-column derivatisation with 4-bromomethyl-7-methoxycoumarin and fluorescence detection, and of neutral sterols (NS), using high performance TLC are given elsewhere (Dongowski et al. 2003).

\section{Statistics}

Data are presented as mean values with their standard errors. Data were analysed by one-way ANOVA with dietary groups as fixed factors. Differences between the control group, given an oat product-free diet, and the test groups, given the DF-rich oat-based diets, were evaluated by Dunnett's $t$ test and Dunnett's T3 test for multiple post hoc comparisons. When variances were heterogeneous, data were log-transformed before analysis (concentrations of cholesterol in caecal contents; taurocholic and taurochenodeoxycholic acid in colonic contents; $\alpha$-muricholic acid at weeks 2 and 4, chenodeoxycholic acid at weeks 4 and 6 , coprostanol and cholestanone at week 4 in faeces; concentrations of propionic and $n$-valeric acid in caecal contents at week 6; weights of ileal contents at week 6; DM content of faeces at week 6; count numbers of Bacteroides at week 6; food and water intake at weeks 1 and 2). Differences with a value $P<0.05$ were considered significant. Statistical analysis was performed using Statistical Package for Social Sciences software SPSS 11.0 (SPSS Inc., Chicago, IL, USA).

\section{Results}

\section{Oat-based products and experimental diets}

A series of oat-based products consisting of oat flour, oat bran and/or Novelose 330 in extruded, autoclaved or untreated form were used for the experiments. The composition of these products is given in Table 2. The oat-based products differed in their contents of $\beta$-glucan $(30-92 \mathrm{~g} / \mathrm{kg})$, RS $(4-128 \mathrm{~g} / \mathrm{kg})$, soluble 
Table 2. Composition and properties of the oat-based products

\begin{tabular}{|c|c|c|c|c|c|}
\hline Oat-based product & $\mathrm{F}$ & $\mathrm{FN}$ & $\mathrm{B}$ & $\mathrm{BN}$ & F\# \\
\hline \multicolumn{6}{|l|}{ Ingredient (g/kg) } \\
\hline Oat flour & 1000 & 800 & & & 1000 \\
\hline Oat bran & & & 1000 & 800 & \\
\hline Novelose 330 & & 200 & & 200 & \\
\hline \multicolumn{6}{|l|}{ Analysed composition $(\mathrm{g} / \mathrm{kg})^{*}$} \\
\hline Starch & 586 & 567 & 369 & 435 & 529 \\
\hline Resistant starch & 4 & 128 & 5 & 114 & 58 \\
\hline Protein & 159 & 129 & 192 & 164 & 145 \\
\hline Lipids & 61 & 50 & 89 & 59 & 62 \\
\hline Soluble DF & 39 & 26 & 90 & 72 & 47 \\
\hline Insoluble DF & 47 & 55 & 129 & 100 & 33 \\
\hline Non-digestible oligosaccharides & 32 & 27 & 13 & 18 & 18 \\
\hline Total DF† & 122 & 236 & 237 & 304 & 156 \\
\hline$\beta$-Glucan & 41 & 30 & 92 & 69 & 39 \\
\hline \multicolumn{6}{|l|}{ Functional properties } \\
\hline Water uptake $\left(\mathrm{g} \mathrm{H}_{2} \mathrm{O} / \mathrm{g}\right)$ & 5.69 & 4.59 & $2 \cdot 88$ & 4.63 & 2.57 \\
\hline Acid extract viscosity $\ddagger$ & 67.5 & $51 \cdot 0$ & $165 \cdot 4$ & $115 \cdot 1$ & 4.5 \\
\hline Molecular weight of $\beta$-glucan $(\mathrm{kDa}) \S$ & $94 \cdot 8$ & $145 \cdot 8$ & $132 \cdot 4$ & $131 \cdot 2$ & $49 \cdot 1$ \\
\hline
\end{tabular}

F, oat flour; FN, oat flour/Novelose; B, oat bran; BN, oat bran/Novelose; F\#, oat flour (autoclaved).

* Mean values of at least duplicates; for $\beta$-glucan and resistant starch, $n$ 4-6.

† Sum of soluble and insoluble dietary fibre, non-digestible oligosaccharides and resistant starch.

$\ddagger$ Relative viscosity.

$\S$ Calculated from intrinsic viscosity using the Mark-Houwink equation.

DF $(26-90 \mathrm{~g} / \mathrm{kg})$, insoluble DF $(33-129 \mathrm{~g} / \mathrm{kg})$ and non-digestible oligosaccharides $(13-32 \mathrm{~g} / \mathrm{kg})$, as well as of lipids, protein and starch. In detail, $\beta$-glucan-rich were the bran-containing products and RS-rich were the Novelose-containing products. However, in autoclaved flour, a higher RS content was also present. The highest soluble, insoluble and total DF values were measured in the bran-containing samples. The proportion of the non-digestible oligosaccharide fraction was relatively high in the oat-based products. The source of most of these non-digestible oligosaccharides is the oligofructose (inulin) fraction of oat. Furthermore, some oligosaccharides, soluble in approximately $80 \%$ ethanol v/v, may be formed from polymeric dietary fibre components during the Association of Official Analytical Chemists' method.

The oat-based products also differed in several of their functional properties. Thus, water uptake was highest in extruded and lowest in autoclaved flour. Extrusion of the bran-Novelose mixture resulted in an increased water uptake compared with the untreated bran (Table 2).

The acid-extract viscosity was highest in the extracts from bran-containing oat products and extremely low in the extract from the autoclaved product (Table 2). After the enzymatic removal of starch and protein from the oat-based products, $\beta$-glucan preparations were isolated. The molecular weights of these preparations, calculated from the intrinsic viscosities using the Mark-Houwink equation, were between approximately 95 and $146 \mathrm{kDa}$ (Table 2). However, the $\beta$-glucan preparation isolated from autoclaved oat flour had a molecular weight of only $49 \mathrm{kDa}$. Functional properties of the oat products such as water-binding or viscosity may play an important role during their passage through the gastrointestinal tract.

Compared with the control diet, the oat-based diets contained more soluble, insoluble and total DF as well as more $\beta$-glucan, but less wheat starch. In Novelose-containing diets and in the diet containing autoclaved oat flour, more than $30 \mathrm{~g} / \mathrm{kg}$ RS was found. Furthermore, $50 \mathrm{~g} / \mathrm{kg}$ microcrystalline cellulose was present in all the experimental diets (Table 1).

\section{Behaviour, food and water intake and weight gain of the rats}

The diets were well accepted by the animals. There were no treatment-related changes in behaviour or appearance of the rats during the experiment, and all the rats remained healthy during the experimental period.

No differences in food intake were found between the groups. The food intake increased in all groups up to week 5. The following food intakes was measured (per rat and week): week 1, 96.8 (SEM 1.2) g; week 2, 121.4 (SEM 1.6) g; week 3, 114.4 (SEM 1.3) g; week 4, 133.4 (SEM 2.1) g; week 5, 135.4 (SEM 2.1) g; week 6, 119.1 (SEM 1.7) g. The total food intake during the experiment was 720.6 (SEM 8.6) g per rat. The water intake increased at least up to week 4 in all groups. In groups consuming the oat-based diets, a higher water intake was measured compared with the control group (Fig. 1). The highest water intake was found in rats fed the bran-containing diet B. There were no differences in weight gain among the groups. The weight of the rats increased as follows: week 0, 86.3 (SEM 0.6) g; week 2, 166.3 (SEM 1.4) g; week 4, 243.0 (SEM 2.2) g; week 6, 303.8 (SEM 3.3) g. Food efficiency that means weight gain (in g) per consumed diet (in g) was similar between the groups.

\section{Serum lipids}

At week 0 , the following characteristics were found: $2 \cdot 11$ (SEM 0.13 ) $\mathrm{mmol} / \mathrm{l}$ total cholesterol; 1.59 (SEM 0.10 ) $\mathrm{mmol} / \mathrm{l} \mathrm{HDL}-$ cholesterol; 0.46 (SEM 0.07) mmol/l LDL-cholesterol; 0.49 (SEM $0.08) \mathrm{mmol} / \mathrm{l}$ triacylglycerols. Because rats had normal serum lipid concentrations, changes during the experiment were relatively low. The differences in selected serum lipids between weeks 6 and 0 are shown in Table 3. Both total and LDL-cholesterol decreased more strongly in most of the groups fed the oatbased diets than in the control group. Triacylglycerols were not uniformly affected by the diet. 


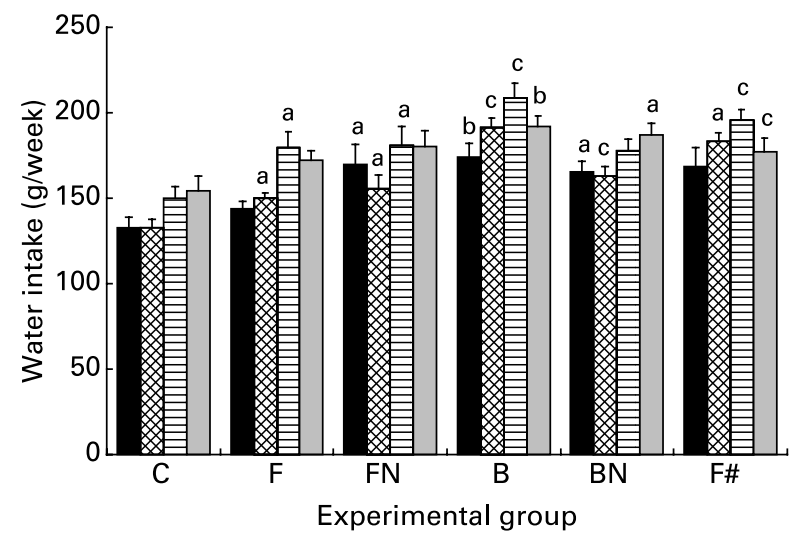

Fig. 1. Water intake of rats $(\mathrm{g} /$ week) fed the control diet $C$ or the oat-based diets F, FN, B, BN and F\# during the experiment. Values are means of ten rats with their standard errors shown by vertical bars. Mean values were significantly different from those of the control group: ${ }^{a} P<0.05,{ }^{b} P<0.005$, ${ }^{c} P<0.001$. $\square$, week $1 ; \otimes$, week 2; $\boxminus$, week 4; $\square$, week 6 . For details of diets, see p. 1013 and Table 1.

\section{Microbial counts}

The numbers of aerobic and anaerobic micro-organisms were higher in rats fed the oat-based diets at week 6 . Whereas counts of coliforms were higher in the controls, more bifidobacteria were found in groups fed the oat-based diets. These differences were greater than one order of magnitude in some groups. The numbers of Bacteroides and Lactobacillus did not differ between the groups (Fig. 2).

\section{Organ mass, intestinal contents and faecal mass}

When the rats were killed at week 6 , selected organs and intestinal contents were removed. Macroscopic alterations were not observed in the organs of any of the rats. There was no difference in the weights of liver, spleen, stomach, and jejunal and ileal walls between the groups at the end of the experiment. The masses of the caecal walls were, however, significantly greater in most of the groups fed the oat-based diets (Table 4).

The wet contents of the caecum and colon were significantly greater, or showed a trend towards being greater, in some test groups. The reason for this effect was the higher content of DF in these diets. Compared with controls, the ileal and caecal contents were up to $50 \%$ and $90 \%$ higher, respectively, in groups fed the oat-based diets. Likewise, higher amounts of content were found in the proximal and distal parts of the colon (up to $80 \%$ and $50 \%$, respectively) in these groups (Table 4).

In addition, a higher proportion of DM was found in intestinal contents of rats fed the oat-based diets for 6 weeks. Thus, in the caecal contents, DM was $20.45 \%$ (SEM $0.90 \%$ ) in the control group and up to $25.46 \%$ (SEM $0.51 \%$ ) in groups fed the oatbased diet. In the colonic contents (proximal), DM increased from $25.05 \%$ (SEM $2.10 \%$ ) in the control group up to $32.00 \%$ (SEM $2.52 \%$ ) in groups fed the oat-based diets.

RS was not found in the caecal contents of the control group as well as of groups F and B. Small amounts of RS, however, appeared in the caecal contents of the groups fed diets containing Novelose or autoclaved oat flour. RS was absent from the contents of the distal colon in all groups.

At week $6, \mathrm{pH}$ values were significantly lower $(P<0.001)$ in all the caecal and colonic contents of rats fed the oat-based diets compared with controls (Fig. 3). The reason for this effect is the higher formation of SCFA as a result of DF fermentation by the intestinal microflora. In the caecum, the lowest $\mathrm{pH}$ values were measured in the bran-fed group. It is interesting that lower average $\mathrm{pH}$ values were present in colonic contents if the diet contained Novelose (FN, BN) compared with the corresponding Novelose-free diets (F, B). This points to a stronger fermentation of RS from Novelose in the colon.

The excreted amounts of DM, determined after freeze-drying of whole faeces collected over $24 \mathrm{~h}$, were significantly different between the control group and the groups fed the oat-based diets at weeks 4 and 6 . Thus, excretion of DM was as follows at the end of the experiment: control group, 3.09 (SEM 0.08) g/ d; group F, 4.54 (SEM 0.25) g/d; group FN, 4.67 (SEM 0.37) g/d; group B, 4.83 (SEM 0.31) g/d; group BN, $4.44($ SEM 0.15$) \mathrm{g} / \mathrm{d}$; group F\#, 4.19 (SEM 0.24) g/d $(P<0.001$; in group F\#, $P<0.005)$.

\section{SCFA in caecal contents}

SCFA were measured in the caecal contents at week 6 . The concentrations of acetate, propionate and butyrate were significantly higher in the whole-caecal contents of all groups fed the oat-based diets compared with controls (wet weight basis). In particular, the bran-containing diets were highly fermentable in the caecum. The extruded flour was fermented more slowly in the caecum than was the autoclaved flour (Fig. 4). In all groups, acetate was the dominant SCFA. More acetate was formed in all test groups than in the control group $(P<0 \cdot 001)$. Significantly higher concentrations of propionate and butyrate were, however, also found in the test groups. Besides higher total amounts of butyrate, the proportion

Table 3. Differences in serum lipids $(\mathrm{mmol} / \mathrm{l})$ between week 6 and week 0 of rats fed control or oat-based diets

(Values are means of ten rats with their standard errors)

\begin{tabular}{|c|c|c|c|c|c|c|}
\hline \multirow[b]{2}{*}{ Diet group } & \multicolumn{2}{|c|}{ Total cholesterol } & \multicolumn{2}{|c|}{ LDL-cholesterol } & \multicolumn{2}{|c|}{ Triacylglycerols } \\
\hline & Mean & SEM & Mean & SEM & Mean & SEM \\
\hline Control & 0.031 & 0.048 & -0.071 & 0.023 & 0.189 & 0.088 \\
\hline Flour & $-0.236^{a}$ & 0.057 & -0.112 & 0.027 & -0.099 & 0.117 \\
\hline Flour/Novelose & $-0.219^{a}$ & 0.073 & -0.135 & 0.034 & 0.081 & 0.081 \\
\hline Bran & -0.087 & 0.077 & $-0.165^{a}$ & 0.025 & 0.321 & 0.054 \\
\hline Bran/Novelose & $-0.335^{b}$ & 0.058 & -0.136 & 0.029 & $-0.165^{a}$ & 0.115 \\
\hline Flour (autoclaved) & -0.062 & 0.065 & $-0.164^{a}$ & 0.015 & 0.292 & 0.072 \\
\hline
\end{tabular}

Mean values were significantly different from those of the control group: ${ }^{\mathrm{a}} P<0.05,{ }^{\mathrm{b}} P<0.005$. 


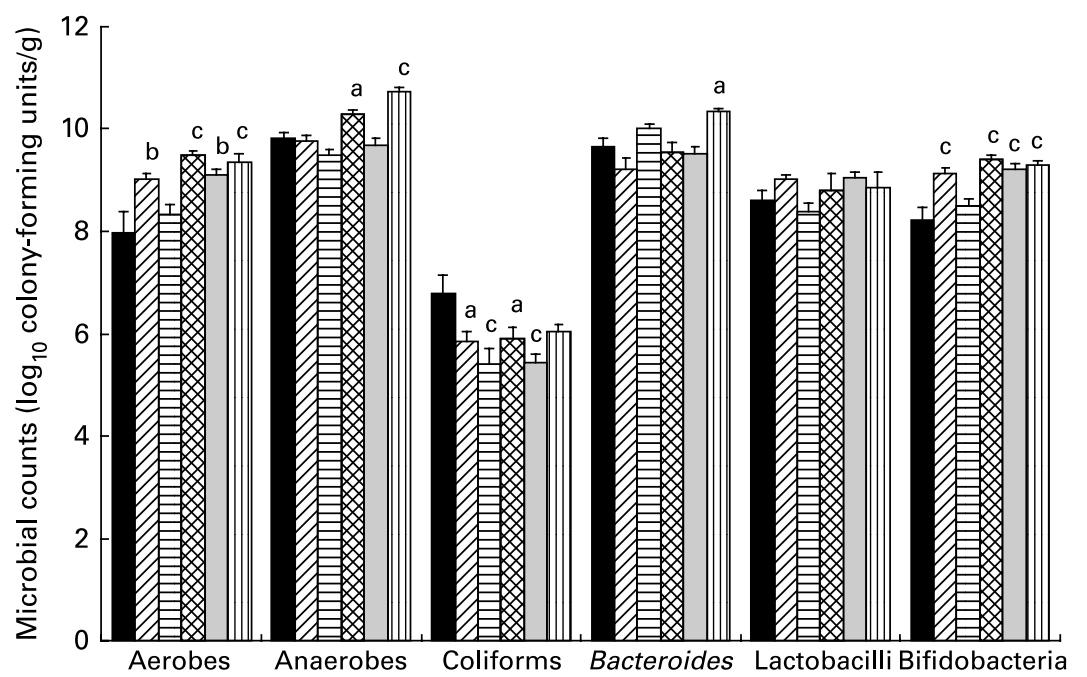

Fig. 2. Microbial counts $\left(\log _{10}\right.$ colony-forming units/g) in the fresh faecal samples of rats fed the control diet $C$ or the oat-based diets $F$, FN, B, BN and F\# for 6 weeks. Values are means of six rats with their standard errors shown by vertical bars. Mean values were significantly different from those of the control group:

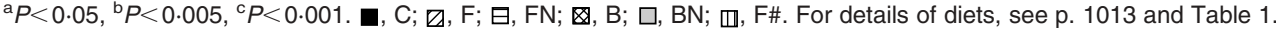

of butyrate increased in all groups fed the oat-based diets. The highest proportion of butyrate was found in the caecal contents of groups $\mathrm{F}(25.5 \%), \mathrm{BN}(23.7 \%)$ and B (19.7\%). The valerates were present in only relatively low amounts. The total SCFA concentration of the caecal contents was: control group, 156.1 (SEM 9.9) $\mu \mathrm{mol}$; group F, 313.9 (SEM 15.0) $\mu \mathrm{mol}$; group FN, 420.5 (SEM 24.9) $\mu \mathrm{mol}$; group B, 590.4 (SEM 37.3) $\mu \mathrm{mol}$; group BN, 609.3 (SEM 54.3) $\mu \mathrm{mol}$; group F\#, 345.5 (SEM 33.1) $\mu \mathrm{mol}$ $(P<0.001$ in all test groups $)$.

Oat bran and Novelose were the best substrates for the microbial production of SCFA. It seems that the autoclaved flour was fermented more quickly than the extruded flour. More SCFA were formed in the caecum of rats given the bran-containing diets. In these dietary groups, more butyrate was also found. The addition of Novelose 330 improved SCFA formation only in combination with oat flour.

\section{Steroids in intestinal contents and faeces}

Concentrations of BA and NS were determined in the caecal and colonic contents at week 6 and in faeces at weeks $0,2,4$ and 6 . On a DM basis, the amount of total BA increased from caecum contents to faeces in all groups.
Besides the individual BA cholic acid, deoxycholic acid, chenodeoxycholic acid, lithocholic acid, and their metabolites such as 7-ketodeoxycholic acid, 12-ketolithocholic acid, hyodeoxycholic acid, ursodeoxycholic acid and $\alpha$ - and $\beta$-muricholic acid, several tauroconjugates (taurocholic acid, taurodeoxycholic acid, taurochenodeoxycholic acid) were present in the intestinal contents. Whereas $22.53 \%$ tauroconjugated BA were found in the caecal contents of the control group, and $16 \cdot 26-17.98 \%$ in the oat-based groups $(P<0 \cdot 001)$, the proportion of tauroconjugates in the colonic contents was only $4.12 \%$ in the control group and $1.08-3.25 \%$ in the test groups $(P<0.05)$. In the faeces, exclusively free BA were present.

In whole-caecal contents, the total BA concentration was: control group, 10.51 (SEM 0.68) $\mu \mathrm{mol}$; group F, 16.31 (SEM 0.45) $\mu \mathrm{mol}$; group $\mathrm{FN}, 22.29$ (SEM 1.14) $\mu \mathrm{mol}$; group B, 18.45 (SEM 0.79) $\mu \mathrm{mol}$; group $\mathrm{BN}, 21.38$ (SEM 0.62) $\mu \mathrm{mol}$; group $\mathrm{F} \#$, 13.38 (SEM 0.33) $\mu$ mol. With exception of the diet containing the autoclaved flour $(P=0 \cdot 067)$, significantly more total BA were present in groups given the oat-based diets compared with controls $(P<0.001)$. In whole-colonic contents, the total BA concentration in the control group was 2.60 (SEM 0.28) $\mu \mathrm{mol}$, whereas that in the groups fed the oat-based diets ranged between 4.23 (SEM 0.34) $\mu \mathrm{mol}$ and $6 \cdot 17$ (SEM 0.34) $\mu \mathrm{mol}(P<0 \cdot 05$ ).

Table 4. Weights of intestinal walls and contents ( $\mathrm{g}$ wet weight) of rats fed control or oat-based diets for 6 weeks (Values are means of ten rats with their standard errors)

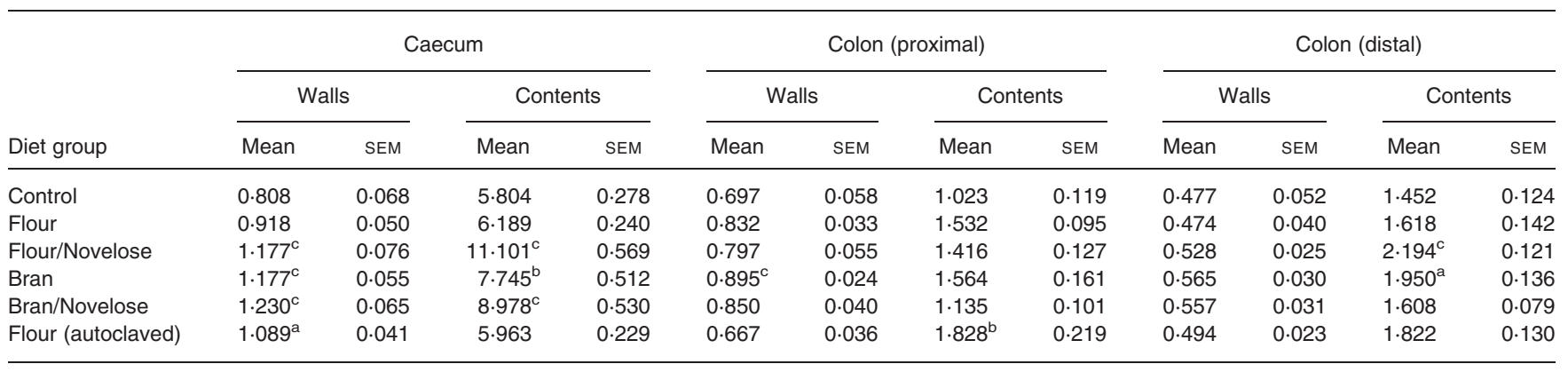

Mean values were significantly different from those of the control group: ${ }^{\mathrm{a}} P<0.05,{ }^{\mathrm{b}} P<0.005,{ }^{\mathrm{c}} P<0.001$. 


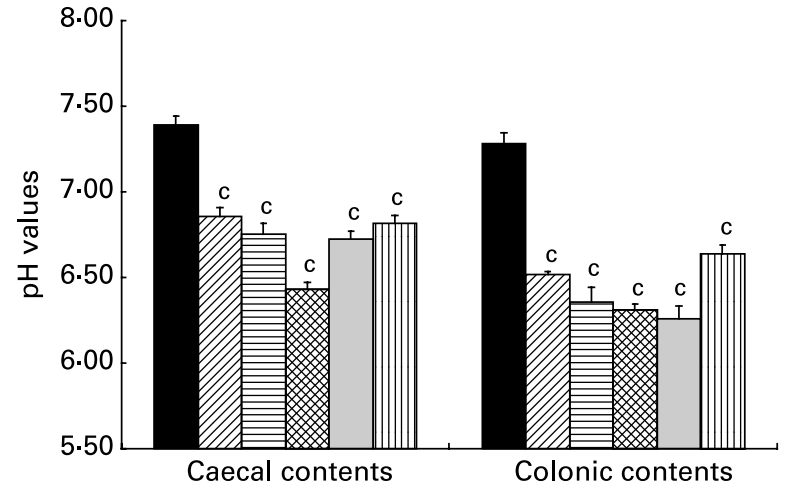

Fig. 3. $\mathrm{pH}$ values of the caecal and colonic contents of rats fed the control diet $\mathrm{C}$ or the oat-based diets F, FN, B, BN and F\# for 6 weeks. Values are means of ten rats with their standard errors shown by vertical bars. Mean values were significantly different from those of the control group: ${ }^{\mathrm{C}} P<0.001$. 口, C; $\square, F ; 日, F N ;, B ; \square, B N ; \square, F \#$. For details of diets, see p. 1013 and Table 1.

During the experiment, the excretion of BA increased to different degrees in each of the groups. Compared with controls, significantly more BA were excreted per day in the groups fed the oat-based diets at weeks 4 and 6 (Fig. 5). The excretion was highest in the bran group and lowest in the group fed the autoclaved oat flour. The partial replacement of oat products by Novelose did not improve the excretion of BA. Concentrations of the individual $\mathrm{BA}$ in the faeces of rats fed the control and oat-based diets for 6 weeks are given in Table 5. In all the test groups, significantly more cholic acid, 7-ketodeoxycholic acid, chenodeoxycholic acid, $\alpha$-muricholic acid, $\beta$-muricholic acid and ursodeoxycholic acid were measured. These BA belong to the so-called primary $\mathrm{BA}$, having a hydroxyl group at $\mathrm{C}$ atom 7 of the steroid nucleus. Primary BA are formed in the liver and dominate in the bile and small intestine. During passage through the lower intestinal tract, a proportion of the primary BA is converted to secondary BA by the action of bacterial enzymes. Secondary BA have no hydroxyl or keto group at $\mathrm{C}$ atom 7 of the steroid nucleus.

In whole-caecal and proximal colonic contents, more primary as well as more secondary BA were present in rats fed the oatbased diets (Fig. 6). High concentrations of primary BA were found in the whole-caecal contents of groups $\mathrm{B}$ and $\mathrm{BN}$, in

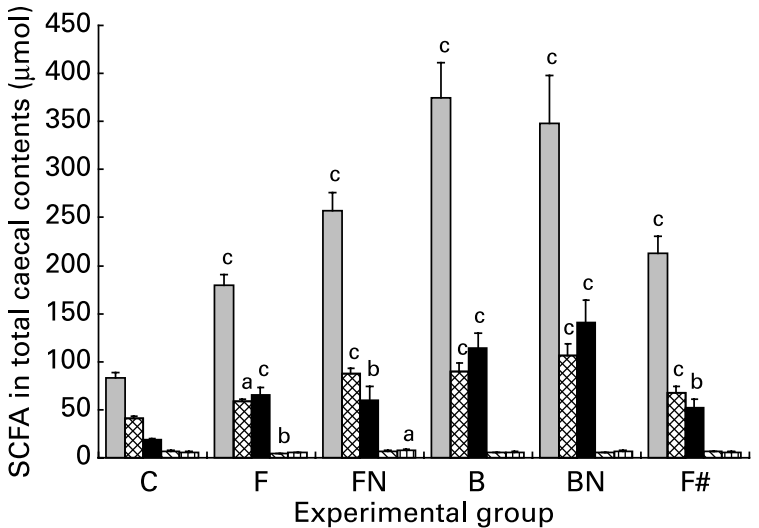

Fig. 4. Individual SCFA in the whole-caecal contents ( $\mu \mathrm{mol}$ ) of rats fed the control diet $\mathrm{C}$ or the oat-based diets F, FN, B, BN and F\# for 6 weeks. Values are means of ten rats with their standard errors shown by vertical bars. Mean values were significantly different from those of the control group: ${ }^{\mathrm{a}} P<0.05,{ }^{\mathrm{b}} P<0.005,{ }^{\mathrm{c}} P<0.001$. $\square$, Acetate; $\otimes$, Propionate; $\mathbf{\square}$, Butyrate; $\square$, iso-Valerate; $\square, n$-Valerate. For details of diets, see p. 1013 and Table 1.

which high concentrations of SCFA were also present. Therefore, besides different rates of interaction between DF components in the diet and $\mathrm{BA}$, and different transport rates of $\mathrm{BA}$ into the caecum, the fermentation of DF seems to play an important role in the formation of secondary BA. The greatest amount of secondary BA was found in group F. In whole contents of proximal colon, a lower concentration of primary and secondary BA appeared in groups fed the Novelose-containing diets. The proportion of primary and secondary BA in faeces at week 6 is given in Fig. 7. In all test groups, significantly more primary and fewer secondary BA $(P<0.001)$ were found than in the control group. Thus, the proportion of primary BA was $36.7 \%$ in the controls and $56.5 \%$ in group BN.

A greater concentration of NS was found in the whole-caecal contents of rats fed the oat-based diets compared with controls $(P<0.001)$ ) control group, 18.47 (SEM 1.41) $\mu \mathrm{mol}$; group $\mathrm{F}$, 26.99 (SEM 0.46) $\mu \mathrm{mol}$; group FN, 40.50 (SEM 2.28) $\mu \mathrm{mol}$; group B, 29.06 (SEM 1.09) $\mu \mathrm{mol}$; group BN, 33.15 (SEM 1.18) $\mu \mathrm{mol}$; group F\#, 24.64 (SEM 0.60) $\mu$ mol. Obviously, Novelose had a high impact on the transport of NS into the caecum.

Table 5. Concentration of individual and total bile acids ( $\mu \mathrm{mol} / \mathrm{g} \mathrm{DM})$ in the faeces of rats fed control or oat-based diets for 6 weeks (Values are means of ten rats with their standard errors)

\begin{tabular}{|c|c|c|c|c|c|c|c|c|c|c|c|c|}
\hline \multirow[b]{2}{*}{ Bile acid } & \multicolumn{2}{|c|}{ Control } & \multicolumn{2}{|c|}{ Flour } & \multicolumn{2}{|c|}{ Flour/Novelose } & \multicolumn{2}{|c|}{ Bran } & \multicolumn{2}{|c|}{ Bran/Novelose } & \multicolumn{2}{|c|}{ Flour (autoclaved) } \\
\hline & Mean & SEM & Mean & SEM & Mean & SEM & Mean & SEM & Mean & SEM & Mean & SEM \\
\hline $\mathrm{CA}$ & 0.938 & 0.022 & $1.372^{c}$ & 0.024 & $1.556^{\mathrm{C}}$ & 0.044 & $1.559^{c}$ & 0.036 & $1 \cdot 841^{\mathrm{C}}$ & 0.038 & $1.004^{c}$ & 0.026 \\
\hline DCA & 1.952 & 0.021 & $2 \cdot 110^{\mathrm{a}}$ & 0.045 & 1.945 & 0.049 & $2 \cdot 270^{\mathrm{c}}$ & 0.059 & $2 \cdot 225^{\mathrm{c}}$ & 0.040 & 1.831 & 0.027 \\
\hline KDCA & 0.267 & 0.011 & $0.385^{c}$ & 0.022 & $0.468^{\mathrm{C}}$ & 0.023 & $0.527^{c}$ & 0.016 & $0.556^{c}$ & 0.024 & $0.357^{c}$ & 0.013 \\
\hline KLCA & 0.802 & 0.012 & $0.903^{b}$ & 0.024 & $0.717^{\mathrm{a}}$ & 0.020 & $0.926^{c}$ & 0.024 & 0.754 & 0.023 & $0.688^{c}$ & 0.016 \\
\hline CDCA & 0.313 & 0.009 & $0.700^{c}$ & 0.021 & $0.701^{\mathrm{c}}$ & 0.012 & $0.639^{c}$ & 0.028 & $0.865^{c}$ & 0.017 & $0.565^{c}$ & 0.017 \\
\hline$\alpha \mathrm{MCA}$ & 1.615 & 0.032 & $2 \cdot 312^{\mathrm{C}}$ & 0.037 & $2.522^{\mathrm{C}}$ & 0.049 & $2 \cdot 775^{\mathrm{c}}$ & 0.045 & $2 \cdot 938^{\mathrm{c}}$ & 0.046 & $2 \cdot 142^{c}$ & 0.043 \\
\hline$\beta M C A$ & 1.315 & 0.037 & $2 \cdot 073^{\mathrm{C}}$ & 0.038 & $1.561^{b}$ & 0.043 & $2 \cdot 208^{\mathrm{C}}$ & 0.047 & $2 \cdot 180^{c}$ & 0.062 & $1.820^{\mathrm{C}}$ & 0.044 \\
\hline HDCA & $2 \cdot 419$ & 0.038 & $1.797^{\mathrm{C}}$ & 0.045 & $1.667^{\mathrm{C}}$ & 0.043 & $1.834^{\mathrm{C}}$ & 0.034 & $1.358^{\mathrm{C}}$ & 0.047 & $1.469^{c}$ & 0.039 \\
\hline UDCA & 0.208 & 0.013 & $0.461^{c}$ & 0.017 & $0.494^{c}$ & 0.020 & $0.297^{b}$ & 0.017 & $0.450^{c}$ & 0.018 & $0.484^{c}$ & 0.023 \\
\hline Total BA & $12 \cdot 384$ & 0.082 & $14 \cdot 706^{c}$ & 0.109 & $13.875^{c}$ & 0.140 & $15 \cdot 925^{c}$ & 0.104 & $15 \cdot 618^{c}$ & 0.142 & $12 \cdot 683$ & 0.093 \\
\hline
\end{tabular}

CA, cholic acid; DCA, deoxycholic acid; KDCA, 7-ketodeoxycholic acid; KLCA, 12-ketodeoxycholic acid; CDCA, chenodeoxycholic acid; LCA, lithocholic acid; MCA, muricholic acid; HDCA, hyodeoxycholic acid; UDCA, ursodeoxycholic acid. BA, bile acid.

Mean values were significantly different from those of the control group: ${ }^{\mathrm{a}} P<0.05,{ }^{\mathrm{b}} P<0.005,{ }^{\mathrm{c}} P<0.001$. 


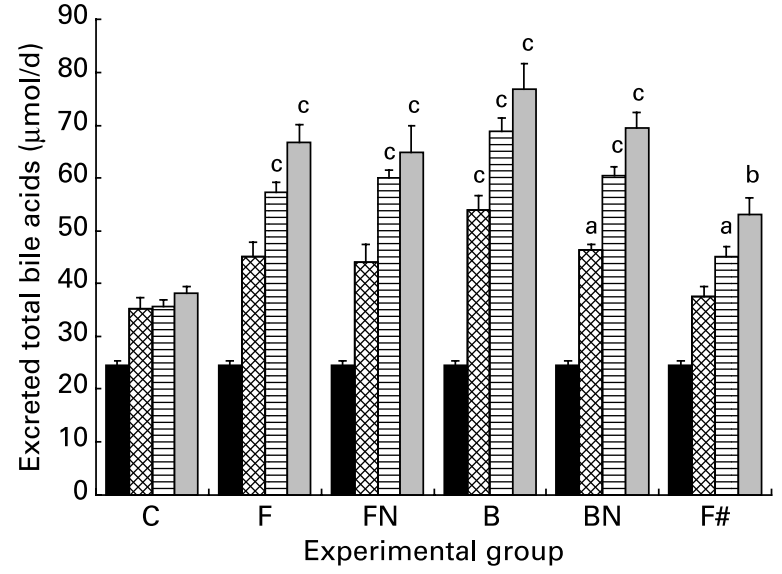

Fig. 5. Excretion of total bile acids $(\mu \mathrm{mol} / \mathrm{d})$ of rats fed the control diet $\mathrm{C}$ or the oat-based diets F, FN, B, BN and F\# during the experiment. Values are means of ten rats with their standard errors shown by vertical bars. Mean values were significantly different from those of the control group: ${ }^{a} P<0.05$, ${ }^{\mathrm{b}} P<0.005,{ }^{\mathrm{c}} P<0.001$. $\square$, week 0 ; $\otimes$, week 2 ; $\boxminus$, week 4 ; $\square$, week 6 . For details of diets, see p. 1013 and Table 1.

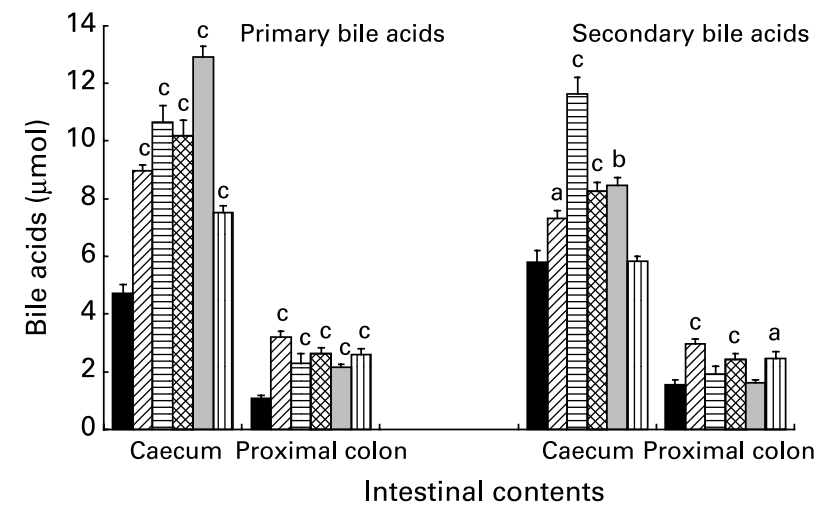

Fig. 6. Primary and secondary bile acids in whole-caecal and proximal colonic contents $(\mu \mathrm{mol})$ of rats fed the control diet $C$ or the oat-based diets $F$, $\mathrm{FN}, \mathrm{B}, \mathrm{BN}$ and $\mathrm{F \#}$ for 6 weeks. Values are means of ten rats with their standard errors shown by vertical bars. Mean values were significantly different from those of the control group: ${ }^{\mathrm{a}} P<0.05,{ }^{\mathrm{b}} P<0.005,{ }^{\mathrm{c}} P<0.001$. $\square, \mathrm{C} ; \square, \mathrm{F}$; E, FN; $\otimes, B ; \square, B N ; \square$, F\#. For details of diets, see p. 1013 and Table 1.

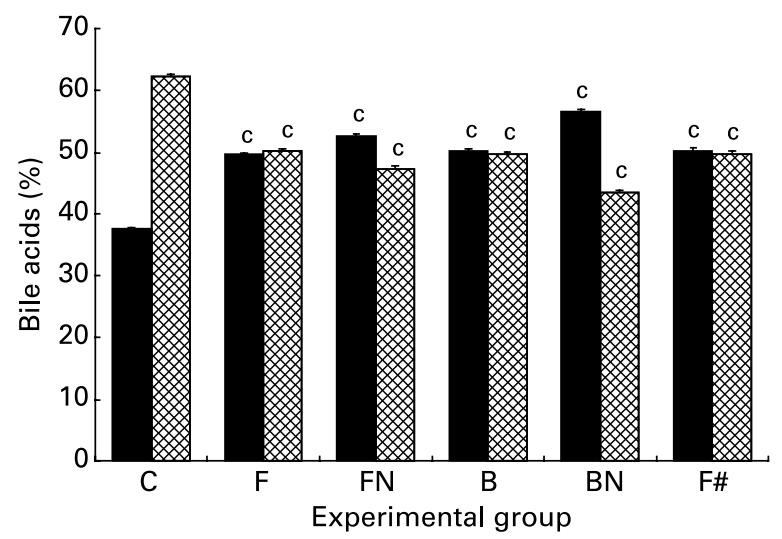

Fig. 7. Proportion of primary and secondary bile acids in the faeces (\%) of rats fed the control diet $C$ or the oat-based diets F, FN, B, BN and F\# for 6 weeks. Values are means of ten rats with their standard errors shown by vertical bars. Mean values were significantly different from those of the control group: ${ }^{c} P<0.001$. . Primary bile acids; $\otimes$, Secondary bile acids. For details of diets, see p. 1013 and Table 1.
Approximately $74 \%$ of the NS were cholesterol and $25 \%$ were coprostanol. Coprostanone was present only in very low amounts. In the contents of the proximal colon, the following total NS concentrations were found: control group, 3.98 (SEM 0.43) $\mu \mathrm{mol}$; group F, 10.83 (SEM 0.56) $\mu \mathrm{mol}$; group FN, 7.34 (SEM 0.98) $\mu \mathrm{mol}$; group B, 9.38 (SEM 0.74) $\mu \mathrm{mol}$; group BN, 6.89 (SEM $0.41) \mu \mathrm{mol}$; group $\mathrm{F} \#, 8.38$ (SEM 0.83$) \mu \mathrm{mol}(P<0.05$ or 0.001 v. control). The highest NS contents were present in the groups fed the diets with extruded flour and bran without Novelose. The NS in the colonic contents consisted of approximately $41 \%$ cholesterol, $56 \%$ coprostanol and 3\% coprostanone.

Whereas the amount and composition of excreted NS were hardly different in the control group throughout the experiment, the concentration of individual NS increased from week 0 to week 6 in groups fed the oat-based diets (with the exception of group F\#). The concentration of individual NS at week 6 is shown in Fig. 8. Most NS were excreted in groups fed the bran-containing diets. The proportion of cholesterol was only $33.7 \%$ in the control group and $29.8-33.1 \%$ in the test groups in the faeces at week 6 . Small amounts of cholestanone appeared in some groups. The following concentrations of total NS/d were excreted at week 6: control group, 63.62 (SEM 1.58) $\mu \mathrm{mol}$; group F, 119.70 (SEM 7.15) $\mu$ mol; group FN, 119.90 (SEM 9.35) $\mu$ mol; group B, 143.97 (SEM 9.02) $\mu \mathrm{mol}$; group BN, 125.94 (SEM 3.57) $\mu$ mol; group F\#, 88.54 (SEM 5.55) $\mu \mathrm{mol}(P<0.001 v$. control; for group F\#, $P=0 \cdot 002)$.

The excretion of total steroids (the sum of BA and NS) increased in all groups during the experiment (Fig. 9). The highest steroid excretion was found in group B. The addition of Novelose (group $\mathrm{BN}$ ) resulted in a lower total amount of excreted steroids. There were no differences in steroid excretion between the groups whose diets contained extruded oat flour. Furthermore, small amounts of phytosterols were present in the faeces (data not shown).

\section{Discussion}

Cereals and cereal products, particularly from whole grains, are the most important source of DF in the Western diet. The amount and composition of DF differ between cereals and cereal cultivars and depend on the technology used during preparation of the cereal products. Despite oat products being well accepted, less than $10 \%$ of total oat production is used for human nutrition.

Starch is usually not eaten in its native state. During cooking processes, starch is gelatinised, with the formation of a starchy paste. With the exception of its resistant fraction, starch can be hydrolysed by enzymes in the small intestine in this state. Extrusion is suitable for the preparation of DF-rich products (Lue et al. 1991; Wang \& Klopfenstein, 1993; Huth et al. 2000). Preparing starchy products that can be eaten directly, for example readyto-eat products, snack foods or breakfast cereals, is a technological process (Colonna et al. 1989). Because of the mechanical and thermal energy input, the morphological and molecular structure of starch is changed. The elevated pressure and high temperature employed during the extrusion process, as well as variables of the ingredients, alter the physical, chemical, functional, sensory and nutritional properties of the extruded products (Asp \& Björk, 1989; Liu et al. 2000). Thus, extrusion results in increased alkaline viscosity and soluble DF content, including that of soluble $\beta$-glucan (Berglund et al. 1994). 


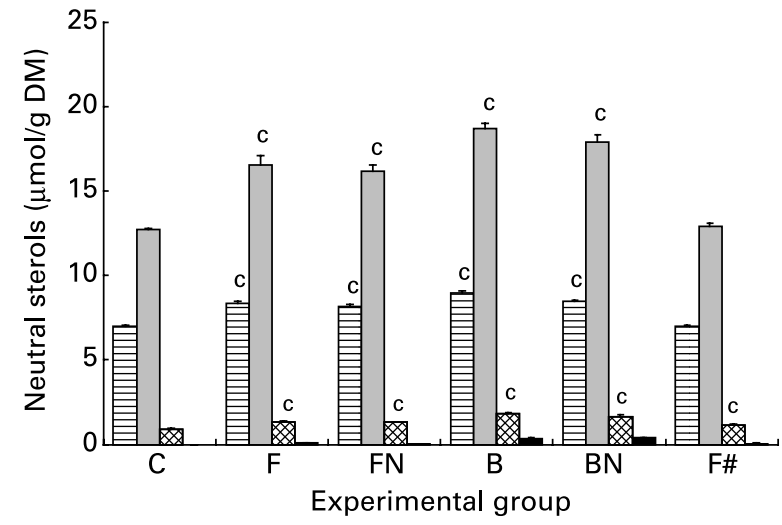

Fig. 8. Excretion of individual neutral sterols $(\mu \mathrm{mol} / \mathrm{g} D M)$ of rats fed the control diet $\mathrm{C}$ or the oat-based diets $\mathrm{F}, \mathrm{FN}, \mathrm{B}, \mathrm{BN}$ and $\mathrm{F \#}$ for 6 weeks. Values are means of ten rats with their standard errors shown by vertical bars. Mean values were significantly different from those of the control group: ${ }^{\mathrm{C}} P<0.001$. $\boxminus$, Cholesterol; $\square$, Coprostanol; $\otimes$, Coprostanone; Cholestanone. For details of diets, see p. 1013 and Table 1.

There is some information on the nutritional properties of cereal extrudates (Asp \& Björk, 1989; Kahlon et al. 1998). Chang et al. (2002) found that extruded cassava starch products blended with either the RS preparation Novelose or oat fibre reduced LDL- and total cholesterol as well as triacylglycerols in hypercholesterolaemic hamsters. Dongowski et al. (2002a, 2003) showed that barley extrudates had beneficial nutritional effects in rats.

By the combined extrusion of cereals and Novelose, products with improved textural properties and higher DF contents, including increased RS concentrations, can be prepared (Anon., 1996). Such products, rich in different types of DF and more or less belonging to the whole-grain type, are multifunctional foods with a high nutritional relevance. Besides RS, $\beta$-glucan was the most important DF component in the oat-based products used. Delaney et al. (2003a) showed that the administration of high $\beta$-glucan concentrations (up to $7 \%$ ) in the diet had no toxic effects on rats. $\beta$-Glucan solutions had a complex rheological behaviour depending on the source material, the technological pre-treatments (Zhang et al. 1998) and the concentration used.

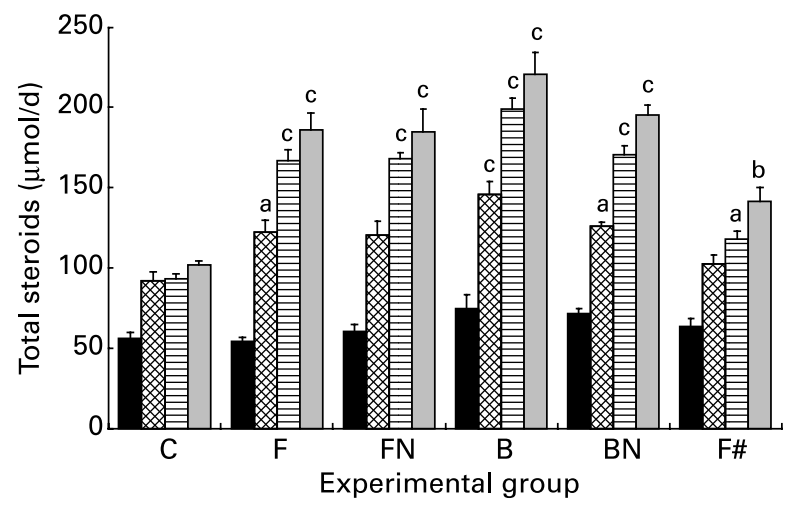

Fig. 9. Excretion of total steroids ( $\mu \mathrm{mol} / \mathrm{d}$ ) of rats fed the control diet $\mathrm{C}$ or the oat-based diets F, FN, B, BN and F\# during the experiment. Values are means of ten rats with their standard errors shown by vertical bars. Mean values were significantly different from those of the control group: ${ }^{a} P<0.05$, ${ }^{\mathrm{b}} P<0.005,{ }^{\mathrm{c}} P<0.001$. 口, week 0 ; $\otimes$, week 2 ; $\boxminus$, week 4 ; $\square$, week 6 . For details of diets, see p. 1013 and Table 1.
The rheological behaviour of $\beta$-glucan isolated from the DFrich oat products was recently evaluated using oscillatory and shear measurements (Dongowski et al. 2005). It was found that $\beta$-glucan extracted from extruded flour and from bran had a dominant viscous behaviour, whereas the $\beta$-glucan from autoclaved flour demonstrated an elastic behaviour. The $\beta$-glucan solutions were structurally viscous, non-Newtonian solutions with a rheostable behaviour. These rheological properties may influence the flow, diffusion or transport behaviour during digestion processes in the small intestine.

We propose that it would be advantageous to apply combinations of cereals (whole-grain flour, bran) and RS in preventive nutrition. RS may differ widely in their characteristics, there being four different types: (1) physically inaccessible starch of whole or partly milled grains; (2) native granular starches; (3) retrograded starches; (4) chemically modified starches. Type 3, the most important RS, can be produced from gelatinised amylose or de-branched starches by controlled re-crystallisation (Asp et al. 1996). Schmiedl et al. (2000) showed that a degree of polymerisation of between 20 and 35 glucose units is optimal for a heat-stable RS type 3, giving a high proportion of butyrate during its fermentation. Novelose 330, used in this study, contained approximately $45 \%$ v/v RS type 3 .

There was no difference in food intake or weight gain among the groups in the present experiment, but water intake was higher in the groups fed the oat-based diets. In a previous study, a higher food intake was observed in rats fed barleybased diets at weeks 5 and 6 (Dongowski et al. 2002a).

Diet influences the balance of intestinal microflora in a complex manner. As a result of DF fermentation, the qualitative and quantitative composition of the microflora (germ numbers, bacterial species) may be changed. This effect was shown for prebiotics, which are mainly non-digestible but fermentable oligosaccharides (Blaut, 2002). In the present study, the intestinal microflora were influenced to only a small degree by the diets used. Feeding the oat-based diets resulted especially in a decrease in the number of coliforms and an increase in bifidobacteria. It should be mentioned that the application of DF-rich barley diets resulted in higher count numbers of Lactobacillus (Dongowski et al. 2002a).

The effects of DF on the intestinal microbiota depend first on the structure and solubility of the DF components and second on their concentration and on the adaptation as well as the application period. Thus, several Bacteroides and Escherichia coli strains were involved in the degradation of pectin (Jensen \& CanaleParola, 1986; Tierny et al. 1994; Dongowski et al. 2000). A stimulation of beneficial bacteria (Bifidobacterium, Lactobacillus) and a partial inhibition of the growth of harmful bacteria (E. coli) were found if inulin, non-digestible oligosaccharides or other prebiotics were applied (Gibson \& Roberfroid, 1995; Gibson, 1998; Kruse et al. 1999). Despite the fact that RS is not considered to be a prebiotic, it still exhibits prebiobitic properties. This effect was also observed in the present experiment.

The presence of viscous DF such as $\beta$-glucan in the oat-based diets, and therefore also in the gut, resulted in higher masses of the caecum and colon walls in most of the test groups. This effect was accompanied by a greater thickness of the walls and changes in the proliferative behaviour of the mucosa (data not shown). Furthermore, the amounts of wet content in the lower intestine were higher in the experimental groups. Such effects were also found in studies with barley-based diets 
(Dongowski et al. 2002a) or pectin (Schmehl et al. 1997). Motility was increased because much more material must be transported through the caecum and colon in the presence of DFrich diets.

Several studies have shown that DF can be fermented in vitro and in vivo. Thus, Drzikova et al. (2005a) found that oat-based extrudates (very similar to the oat products used in the present study) were fermented in vitro with human faecal flora under the formation of high concentrations of SCFA. More SCFA were produced when the extrudates contained more oat bran, soluble and insoluble DF and $\beta$-glucan.

In vivo, $\mathrm{DF}$ are partly or completely fermented by the intestinal microflora, depending on their structural and physicochemical parameters (Bourquin et al. 1996; Wood et al. 2002). Before their fermentation, the poly- and oligosaccharides must be first split into their monosaccharide units by bacterial enzymes. The monosaccharides formed are then further enzymatically decomposed via the Emden-Meyerhof-Parnas and pentose phosphate pathways (Macfarlane \& Gibson, 1996). Some SCFA, such as $n$ - and $i s o$-valeric acid, are formed by the deamination of amino acids as a result of protein fermentation (De Schrijver, 1996). High concentrations of SCFA, particularly butyrate, in the lower parts of the intestinal tract are important for a healthy colonic mucosa. Butyrate, the physiologically most important SCFA, is the major energy source for the colonic epithelium. It regulates cell growth and differentiation as well as playing a role in protection against colon cancer (Topping \& Clifton, 2001; Smith et al. 1998; Jacobasch \& Dongowski, 2000). Propionate has been proposed as an inhibitor of hepatic cholesterol synthesis (Anderson et al. 1990).

$\beta$-Glucan or RS can be fermented relatively rapidly up to $100 \%$, whereas cellulose is usually incompletely or not fermented. Both groups of DF are important for healthy nutrition. The unfermented DF can increase colonic luminal content and lower the transit time through the large intestine, as well as binding water and 'diluting' carcinogens and toxic substances. On the other hand, fermentable DF are an essential source for the formation of SCFA.

We found higher total concentrations of SCFA and higher proportions of butyrate in the caecal contents of rats given the oatbased diets compared with the control group. SCFA formation was influenced by DF composition, DF concentration in the diets and the technological pre-treatment of the oat products.

As an essential component of the mixed micelles, BA are necessary for lipid digestion in the small intestine. They are normally almost completely absorbed in the ileum by active and passive mechanisms, and are transported to the liver via the enterohepatic circulation (Hofmann, 1994). Several DF can interact with BA under the conditions found in the small intestine (Hoagland \& Pfeffer, 1987; Dongowski, 1995) or may disturb fat digestion. These effects result in a lower reabsorption of $\mathrm{BA}$, in their greater transport towards the large intestine (Zhang et al. 1992), in their increased microbial conversion (such as deconjugation and dehydroxylation) and finally in their higher excretion (Zhang et al. 1993; Marlett et al. 1994; Lia et al. 1997; Dongowski et al. 2003). Therefore, the increased excretion of BA requires an increased hepatic synthesis of BA from cholesterol in the blood (Andersson et al. 2002). This is a major hypocholesterolaemic pathway, occurring especially in hypercholesterolaemic individuals or animals (Braaten et al. 1994; Garcia-Diez et al. 1996; Chang et al. 2002). Hydrophobic effects seem to play a role in the interactions between BA and DF (Dongowski, 1995). Furthermore, these interactions may be influenced by the molecular weight and viscosity of isolated DF preparations or by the surface, particle size, composition, botanical source and pre-treatment of DF preparations with cell wall structures (Mongeau \& Brassard, 1982; Huang \& Dural, 1995; Dongowski \& Ehwald, 1999; Kahlon \& Woodruff, 2003; Kotcharian et al. 2004).

A strong interaction was found between digested oat-based extrudates and $\mathrm{BA}$ in vitro. The binding of $\mathrm{BA}$ increased with increasing proportions of oat bran, total DF and insoluble DF, as well as with increasing contents of $\beta$-glucan in the extrudates. Dihydroxy BA were bound more strongly to the extrudates than were trihydroxy BA. These interactions were greater at $\mathrm{pH} 5.0$ than at pH 6.5 (Drzikova et al. 2005a). Likewise, Kahlon \& Woodruff (2003) found an interaction between BA and cereal brans.

In the intestinal contents of rats fed the oat-based diets, more total BA were present compared with the control group. Likewise, BA excretion was higher in these groups, an exception being the group fed the autoclaved oat flour. Oat bran was most effective in BA transport into the lower parts of intestinal tract and excretion. The molecular weight of DF such as $\beta$-glucan and the degree of destruction of the plant cell walls seem to play a role in interactions with BA. Such effects may occur during technological treatments (cooking, extrusion, autoclaving, etc.) or during passage through the upper gastrointestinal tract (Sundberg et al. 1996; Johansen et al. 1997; Robertson et al. 1997).

As a result of the lower $\mathrm{pH}$ of the intestinal contents in groups fed the oat-based products, more primary BA and a lower proportion of secondary BA were found. The concentration of secondary BA was, however, relatively high in the test groups. Secondary BA are formed from primary BA by enzymatic $7 \alpha$-dehydroxylation of the steroid nucleus. Such activity was found in Eubacterium and Clostridium. Other enzymatic actions may lead to the insertion of $\mathrm{OH}$ groups at $\mathrm{C}$ atom 6 , the formation of $\beta-\mathrm{OH}$ groups from $\alpha-\mathrm{OH}$ groups, or the formation of keto groups from $\mathrm{OH}$ groups on the steroid nucleus (Baron \& Hylemon, 2000). The involvement of secondary BA in colon carcinogenesis is not yet clear (Hofstad et al. 1998; Roy et al. 1999). Certain secondary BA (e.g. deoxycholic acid, lithocholic acid) may be cytotoxic and may promote colon carcinogenesis when present in abnormally high concentrations (Owen, 1997). Cytotoxicity depends on the hydrophobicity of the BA (Hofmann, 1999). The best strategy to overcome the problematical effects of BA in the colon is a DF-rich diet. The following effects may occur in the presence of DF: decrease of transit time; dilution of BA; inclusion of BA in the swollen, unfermented DF fraction; lowering of the proportion of secondary $\mathrm{BA}$; improvement in health of the colon mucosa by higher concentrations of SCFA; a healthy microflora. Thus, butyrate and deoxycholic acid appear to interact in a complex and antagonistic manner to selectively modulate crypt base and surface proliferation in the rat colon (Velázquez et al. 1997). It was also shown in the present study that intestinal butyrate was increased in groups fed the oat-based diets.

Likewise, more NS were present in the caecal and colonic contents, as well as in the faeces, of the test groups. A higher excretion rate of NS is connected with a lower absorption of cholesterol. Coprostanol formed from cholesterol by intestinal microflora (Baron \& Hylemon, 2000) was the main excreted NS. Similar effects were found in rats fed DF-rich, barley-based diets (Dongowski et al. 2003). Furthermore, more total steroids 
were excreted in almost all groups given extruded oat-based diets or oat bran.

Despite a higher excretion of BA, the effects of the oat-based diets on serum lipid concentration were low because the animals had normal plasma lipid concentrations.

Generally speaking, RS has a reduced caloric content and lowers the postprandial glucose and insulin responses (Granfeldt et al. 1995). As has also been shown in the present study, the most important effect of RS consumption is the increased intestinal SCFA concentration, including a high proportion of butyrate. In several studies, it was found that the application of RS could result in a lower excretion of BA and NS (Hylla et al. 1998; Langkilde et al. 1998, 2002). It therefore seems possible that changing the cereal-RS relations can modulate the transport of BA towards the lower parts of the intestinal tract, their partial conversion to secondary BA and their excretion. In addition, van Munster et al. (1994) found that faecal water cytotoxicity and colonocyte proliferation were lowered by RS diets. Jacobasch et al. (1999) showed effects of RS on inflammatory bowel diseases. Some studies indicate that RS may be protective against tumour development, whereas no protection has been found in other studies (Martin et al. 2000; Topping \& Clifton, 2001).

There is some confusion in the literature regarding the relationship between DF intake and cancer, especially from the data of several large cohort studies. Thus, Fuchs et al. (1999) and other authors (e.g. data from the Nurses Health Study) found no relationship between DF intake and colorectal cancer. In contrast to these epidemiological evaluations, positive effects of DF on inflammatory bowel diseases and colorectal cancer have been shown by most experimental studies (Kritchevsky \& Bonfield, 1995; Mälkki \& Cummings, 1996; Hartemink, 1997; Spiller, 2001; van der Kamp et al. 2004). Recently, Bingham et al. (2003) found, in the European Prospective Investigation into Cancer and Nutrition cohort study, that an approximate doubling of total DF intake from food could reduce the risk of colorectal cancer by $40 \%$. Whereas in cohort studies DF content is calculated from data reported in questionnaires, well-defined and exactly determined DF components are applied in most experimental studies. As shown in the present study, individual DF components or groups, such as $\beta$-glucan and RS or the grown cell wall structure, differ in their structure and functional properties and may have special effects in the gastrointestinal tract.

One question that can be raised relates to whether the concentration of oat products used in the test diets of the present study was too high. The test diets, however, contained all nutrients in their recommended concentrations. We replaced a great part of the wheat starch, used in the control diet, by the oat products, consisting likewise mainly of starch. Naturally, the test diets were lower in energy and higher in DF than the control diet. In a former study, we used test diets consisting of $500 \mathrm{~g} / \mathrm{kg}$ barley products (Dongowski et al. 2002a, 2003). There were no differences in weight gain between all groups and no illness seen in the rats, either in the experiment with the barley-containing diet or with the oat-containing diets in the present experiment. On the other hand, a long-term application of such high concentrations of oat products is not practicable in human nutrition. In pilot studies, subjects were given $100 \mathrm{~g}$ of an oat-based or a barley-based DF-rich extrudate per day for 4 weeks in addition to their habitual diet (Drzikova et al. 2005b; G. Dongowski et al. unpublished results). Principally, it appears that there is no problem consuming this amount of extrudate for a longer period.
Using the definition of DF given by the Food and Nutrition Board of the National Academy of Sciences of the USA (Anon., 2002), the RS-containing products investigated in the present study can be described as functional fibre.

In conclusion, the application of the DF-rich, oat-based diets had a variety of beneficial physiological and protective effects in rats depending on the composition and amount of the DF, their technological pre-treatment and their functional properties. The major effects were connected with the fermentation of DF components and the higher formation and absorption of SCFA, as well as with the higher excretion of steroids. Further studies are requested in man to prove whether a regular consumption of such oat-based products is helpful in preventing inflammatory bowel diseases and colon cancer, as well as against hypercholesterolaemia.

\section{Acknowledgements}

The authors are grateful to Annedore Habel for preparation of the oat-based products, Dr C. Thöne-Reinecke and Dr K. MüllerSchmehl for their assistance in the animal experiments, and Karin Richter, Bärbel König, Elke Thom, Irmgard Thomas, and Horst Maischack for their skilful technical assistance. Thanks also go to Dr A. Lorenz (Gesellschaft für Innovative Mikrobiologie $\mathrm{mbH}$, Wildenbruch, Germany) for measuring the microbial counts, and to the Hygiene Institut Labordiagnostik Potsdam GbR (Potsdam, Germany) for measuring the serum lipids. This research project (No. AiF-FV 12716 BR) was supported by the FEI (Forschungskreis der Ernährungsindustrie e.V., Bonn), the AiF and the Ministry of Economics and Labour.

\section{References}

Anderson JW, Deakins DA \& Bridges SR (1990) Soluble fiber hypocholesterolemic effects and proposed mechanisms. In Dietary Fiber Chemistry, Physiology, and Health Effects, pp. 339-363 [D Kritchevsky, C Bonfield and JW Anderson, editors]. New York: Plenum Press.

Andersson M, Ellegård L \& Andersson H (2002) Oat bran stimulates bile acid synthesis within $8 \mathrm{~h}$ as measured by $7 \alpha$-hydroxy-4-cholesten-3one. Am J Clin Nutr 76, 1111-1116.

Anon (1996) Mit Ballast und doch leicht. Extrudierte Produkte mit Novelose [With DF but still light. Extruded products with Novelose]. Lebensmittel-Technik 28, 40-42.

Anon (2002) Dietary Reference Intakes for Energy, Carbohydrates, Fiber, Fat, Protein and Amino Acids (Macronutrients). 7. Dietary, Functional, and Total Fiber. National Academy of Sciences, USA.

Arrigoni E, Caprez A, Neukom H \& Amadò R (1987) Determination of water uptake by an automated method. Lebensm Wiss Technol 20, 263-264.

Asp NG \& Björk I (1989) Nutritional properties of extruded foods. In Extrusion Cooking, pp. 399-434 [C Mercier, P Linko and UN Harper, editors]. St Paul, MN, USA: American Association of Cereal Chemists.

Asp NG, van Amelsvoort JMM \& Hautvast JGAJ (1996) Nutritional implications of resistant starch. Nutr Res Rev 9, 1-31.

Baron SF \& Hylemon PB (2000) Biotransformation of bile acids, cholesterol, and steroid hormones. In Gastrointestinal Microbiology. Gastrointestinal Ecosystems and Fermentations, pp. 470-510 [RI Mackie and BA White, editors], vol. 1. New York: Chapman \& Hall.

Berglund PT, Fastnaught CE \& Holm ET (1994) Physicochemical and sensory evaluation of extruded high-fiber barley diet. Cereal Chem 71, 91-95. 
Bingham SA, Day NE, Luben R, Ferrari P, Slimany N, Norat T, ClavelChapelon F, Kesse E, Nieters A, Boeing H et al. (2003) DF in food and protection against colorectal cancer in the European Prospective Investigation into Cancer and Nutrition (EPIC): an observational study. Lancet 361, 1496-1501.

Blaut M (2002) Relationship of prebiotics and food to intestinal microflora. Eur J Nutr 41, Suppl. 1, I/11-I/16.

Bornet F (1993) Technological treatments of cereals. Repercussions on the physiological properties of starch. Carbohydr Polym 21, 195-203.

Bourquin LD, Titgemeyer E \& Fahey GC (1996) Fermentation of various dietary fiber sources by human fecal bacteria. Nutr Res 16, 1119-1131.

Braaten JT, Wood PJ, Scott FW, Riedel KD, Poste LM \& Collins MW (1991) Oat gum, a soluble fiber which lowers glucose and insulin in normal individuals after an oral glucose load: comparison with guar gum. Am J Clin Nutr 53, 1425-1430.

Braaten TJ, Wood PJ, Scott FW, Wolynetz MS, Lowe MK, Bradley-White P \& Collins MW (1994) Oat $\beta$-glucan reduces blood cholesterol concentration in hypercholesterolemic subjects. Eur J Clin Nutr $\mathbf{4 8}$, $465-474$.

Brighenti F (1997) Simple method for quantitative analysis of short chain fatty acids in serum by gas-liquid chromatography. In Plant Polysaccharides in Human Nutrition: Structure, Function, Digestive Fate and Metabolic Effects, pp. 114-119 [F Guillon, G Abraham, R Amadò, H Andersson, NG Asp, KE Bach Knudsen, M Champ and J Robertson, editors]. Nantes: Institute National de la Recherches Agronomique.

Brouns F, Kettlitz B \& Arrigoni E (2002) Resistant starch and "the butyrate revolution". Trends Food Sci Technol 13, 251-261.

Chang YK, Martinez-Flores HE, Martinez-Bustos F \& Sgarbieri VC (2002) Effect of extruded products made with cassava starch blended with oat fiber and resistant starch on the hypocholesterolemic properties as elevated in hamsters. Nutraceut Food 7, 133-138.

Colonna P, Tayeb J \& Mercier C (1989) Extrusion cooking of starch and starchy products. In Extrusion Cooking, pp. 247-319 [C Mercier, P Linko and JM Harper, editors]. St Paul, MN, USA: American Association of Cereal Chemists.

Cummings JH \& Frølich W (1993) DF Intake in Europe. A Survey Conducted by the Members of the Management Committee of COST 92. Luxembourg: Office for Official Publications of the European Communities.

Daniel M, Wisker E, Rave G \& Feldheim W (1997) Fermentation in human subjects of nonstarch polysaccharides in mixed diets, but not in a barley fiber concentrate, could be predicted by in vitro fermentation using human fecal inocula. J Nutr 127, 1981-1988.

Delaney B, Carlson T, Frazer S, Zheng T, Hess R, Ostevgren K, Kierzek K, Hawovth J, Knutson N, Junker K et al. (2003a) Evaluation of the toxicity of concentrated barley $\beta$-glucan in a 28-day feeding study in Wistar rats. Food Chem Toxicol 41, 477-487.

Delaney B, Nicolosi RJ, Wilson TA, Carlson T, Frazer S, Zheng GH, Hess R, Ostergren K, Haworth J \& Knutson N (2003b) $\beta$ Glucan fractions from barley and oats are similarly antiatherogenic in hypercholesterolemic Syrian golden hamsters. J Nutr 133, 468-495.

De Schrijver R (1996) Fermentation products in the large intestine. In DF and Fermentation in the Colon, pp. 79-93 [Y Mälkki and JH Cummings, editors]. Luxembourg: Office for Official Publications of the European Communities.

Deutsche Gesellschaft für Ernährung (2004) Ernährungsbericht 2004 [Nutrition Report 2004]. Bonn: Deutsche Gesellschaft für Ernährung e.V.

Dongowski G (1995) Influence of pectin structure on the interaction with bile acids under in vitro conditions. Z Lebensm Unters Forsch 201, 390-398.

Dongowski G, Drzikova B, Senge B, Blochwitz R, Gebhardt E \& Habel A (2005) Rheological behaviour of $\beta$-glucan preparations from oat products. Food Chem 93, 279-291.
Dongowski G \& Ehwald R (1999) Binding of water, oil and bile acids to dietary fibers of the cellan type. Biotechnol Progr 15, 250-258.

Dongowski G, Huth M \& Gebhardt E (2003) Steroids in the intestinal tract of rats are affected by dietary-fibre-rich barley-based diets. Br J Nutr 90, 895-906.

Dongowski G, Huth M, Gebhardt E \& Flamme W (2002a) Dietary fiberrich barley products beneficially affect the intestinal tract of rats. $J$ Nutr 132, 3704-3714.

Dongowski G, Lorenz A \& Anger H (2000) Degradation of pectin with different degrees of esterification by Bacteroides thetaiotaomicron isolated from human gut flora. Appl Environ Microbiol 66, 1321-1327.

Dongowski G, Lorenz A \& Proll J (2002b) The degree of methylation influences the degradation of pectin in the intestinal tract of rats and in vitro. J Nutr 132, 1935-1944.

Doublier J-L \& Wood PJ (1995) Rheological properties of aqueous solutions of $(1 \rightarrow 3)(1 \rightarrow 4)-\beta$-D-glucan from oats (Avena sativa L.). Cereal Chem 72, 335-340.

Drzikova B, Dongowski G, Gebhardt E \& Habel A (2005a) The composition of DF-rich extrudates from oat affects bile acid binding and fermentation in vitro. Food Chem 90, 181-192.

Drzikova B, Dongowski G \& Gebhardt E (2005b) Ernährungs physiologische wirkungen eines Extrudats aus Hafermehl and Novelose [Nutritional effects of an extrudate from oatmeal and Novelose]. Getreidetechologie/Cereal Technol 59, 173-181.

Emmons CL \& Peterson DM (1999) Antioxidant activity and phenolic contents of groats and hulls. Cereal Chem 76, 902-906.

Englyst HN, Klingman SM \& Cummings JH (1992) Classification and measurement of nutritionally important starch fractions. Eur J Clin Nutr 46, Suppl. 2, S33-S50.

Fuchs CSEL, Giovannucci GA, Colditz GA, Hunter DJ, Stampfer MJ, Rosner B, Speizer FE \& Willett WC (1999) Dietary fiber and risk of colorectal cancer and adenoma in women. $N$ Engl J Med 340, 169-176.

Garcia-Diez F, Garcia-Mediavilla V, Bayon JE \& Gonzalez-Gallego J (1996) Pectin feeding influences fecal bile acid excretion, hepatic bile acid synthesis and serum cholesterol in rats. $J$ Nutr 126, 1766-1771.

Gebhardt E, Habel A, Dongowski G, Drzikova B \& Hampshire J (2004) Multifunktionelle Ballaststofflebensmittel auf Basis von Hafer [oat-based Multifunctional DF-containing foods]. Getreidetechnologie/Cereal Technol 58, 80-85.

Gibson GR (1998) Dietary modulation of the human gut microflora using prebiotics. Br J Nutr 80, Suppl. 2, S209-S212.

Gibson GR \& Roberfroid MB (1995) Dietary modulation of the colonic microbiota: introducing the concept of prebiotics. J Nutr $\mathbf{1 2 5}$, 1401-1412.

Granfeldt Y, Drews A \& Björck I (1995) Arepas made from high amylose corn flour produce favorable low glucose and insulin responses in healthy humans. J Nutr 125, 459-465.

Hampshire J (1998) Zusammensetzung und ernährungsphysiologische Qualität von Hafer [Composition and nutritional quality of oat]. Ernährung/Nutrition 22, 505-508.

Hartemink R (1997) Non-digestible Oligosaccharides: Healthy Food for the Colon? Wageningen, The Netherlands: Graduate School VLAG.

Hecker KD, Meier ML, Newman RK \& Newman CW (1998) Barley $\beta$-glucan is effective as a hypocholesterolaemic ingredient in foods. J Sci Food Agric 77, 179-183.

Hoagland PD \& Pfeffer PE (1987) Cobinding of bile acids to carrot fiber. J Agric Food Chem 35, 316-319.

Hofmann A (1994) Intestinal absorption of bile acids and biliary constituents. The intestinal component of the enterohepatic circulation and the integrated system. In Physiology of the Gastrointestinal Tract, 3rd edn., pp. 1845-1865 [LR Johnson, editor]. New York: Raven Press.

Hofmann AF (1999) The continuing importance of bile acids in liver and intestinal disease. Arch Intern Med 159, 2647-2658.

Hofstad B, Vatn MH, Andersen S, Owen RW, Larsen S \& Osnes M (1998) The relationship between faecal bile acid profile with or without 
supplementation with calcium and antioxidants on recurrence and growth of colorectal polyps. Eur J Cancer Prevent 7, 287-294.

Huang C-M \& Dural NH (1995) Adsorption of bile acids to several type food fiber. J Food Proc Engin 18, 243-266.

Huth M, Dongowski G, Gebhardt E \& Flamme W (2000) Functional properties of DF enriched extrudates from barley. Cereal Sci 32, 115-128.

Hylla S, Gostner A, Dusel G, Anger H, Bartram HP, Christl SU, Kasper H \& Scheppach W (1998) Effects of resistant starch on the colon in healthy volunteers: possible implications for cancer prevention. Am J Clin Nutr 67, 136-142.

Jacobasch G \& Dongowski G (2000) Ballaststoffe mit spezifischen Wirkungen [Dietary fibres with specific effects]. In Praxishandbuch Functional Foods, pp. 1-34 [HF Erbersdobler and AH Meyer, editors]. Hamburg: Behr's Verlag.

Jacobasch G, Schmiedl D, Kruschewski M \& Schmehl K (1999) Dietary resistant starch and chronic inflammatory bowel diseases. Int J Colorectal Dis 14, 201-211.

Jensen NS \& Canale-Parola E (1986) Bacteroides pectinophilus sp. nov. and Bacteroides galacturonicus sp. nov.: two pectinolytic bacteria from the human intestinal tract. Appl Environ Microbiol 52, 880-887.

Johansen HN, Bach Knudsen KE, Wood PJ \& Fulcher RG (1997) Physico-chemical properties and the degradation of oat bran polysaccharides in the gut of pigs. J Sci Food Agric 73, 81-92.

Kahlon TS, Chow FI, Knuckles BI \& Chiu MM (1993) Cholesterol-lowering effects in hamsters of $\beta$-glucan-enriched barley fraction, dehulled whole barley, and oat bran and their combinations. Cereal Chem 70, 435-440.

Kahlon TS, Edwards RH \& Chow FI (1998) Effect of extrusion on hypocholesterolemic properties of rice, oat, corn, and wheat bran diets in hamsters. Cereal Chem 75, 897-903.

Kahlon TS \& Woodruff CL (2003) In vitro binding of bile acids by rice bran, oat bran, barley and beta-glucan enriched barley. Cereal Chem 80, 260-263.

Kalra S \& Jood S (2001) Effect of dietary barley $\beta$-glucan on cholesterol and lipoprotein fractions in rats. J Cereal Sci 32, 141-145.

Kerckhoffs DAJM, Brouns F, Hornstra G \& Mensink RP (2002) Effects on human serum lipoprotein profile of $\beta$-glucan, soy protein and isoflavones, plant sterols and stanols, garlic and tocotrienols. J Nutr 132, 2494-2505.

Kotcharian A, Kunzek H \& Dongowski G (2004) The influence of variety on the enzymatic degradation of carrots and on functional and physiological properties of the cell wall materials. Food Chem 87, 231-245.

Kritchevsky D \& Bonfield C (1995) Dietary Fiber in Health and Disease. St Paul, MN, USA: Eagan Press.

Kruse HP, Kleessen B \& Blaut M (1999) Effects of inulin on faecal Bifidobacteria in human subjects. Br J Nutr 82, 375-382.

Langkilde AM, Champ M \& Andersson H (2002) Effects of high-resistant-starch banana flour $\left(\mathrm{RS}_{2}\right)$ on in vitro fermentation and the small bowel excretion of energy, nutrients, and sterols: an ileostomy study. Am J Clin Nutr 75, 104-111.

Langkilde AM, Ekwall A, Björck I, Asp NG \& Andersson H (1998) Retrograded high-amylose corn starch reduces cholic acid excretion from the small bowel in ileostomy subjects. Eur J Clin Nutr 52, 790-795.

Lia Å, Andersson H, Kekki N, Juhel C, Senft M \& Lairon D (1997) Postprandial lipemia in relation to sterol and fat excretion in ileostomy subjects given oat-bran and wheat test meals. Am J Clin Nutr 66, 357-365.

Liu Y, Hsieh F, Heymann H \& Huff HE (2000) Effect of processing conditions on the physical and sensory properties of extruded oat-corn puff. J Food Sci 65, 1253-1259.

Lue S, Hsieh F \& Huff HE (1991) Extrusion cooking of corn meal and sugar beet fiber: effects on expansion properties, starch gelatinization, and dietary fiber content. Cereal Chem 68, 227-234.

Lupton JR, Morin JL \& Robinson MC (1993) Barley bran flour accelerates gastrointestinal transit time. J Am Diet Assoc 93, 881-885.

McCleary BV \& Mugford DC (1997) Determination of $\beta$-glucan in barley and oat by streamlined enzymatic methods: summary of collaborative study. J Assoc Off Anal Chem Intern 80, 580-583.
Macfarlane GT \& Gibson GR (1996) Carbohydrate fermentation, energy transduction and gas metabolism in the human large intestine. In Gastrointestinal Microbiology, vol. 1 Gastrointestinal Ecosystems and Fermentations, pp. 239-318 [RIM Mackie and BA White, editors]. New York: Chapman and Hall.

Mälkki Y \& Cummings JH (1996) DF and Fermentation in the Colon. Proceedings of COST Action 92. Luxembourg: Office for Official Publications of the European Communities.

Mälkki Y \& Virtanen E (2001) Gastrointestinal effects of oat bran and oat gum - a review. Lebensm Wiss Technol 34, 337-347.

Marlett JA, Hosig KB, Vollendorf NW, Shinnick FL, Haack VS \& Story JA (1994) Mechanism of serum-cholesterol reduction by oat bran. Hepatology 20, 1450-1457.

Martin JMM, Dumon HJW, Lecannu G \& Champ MMJ (2000) Potato and high-amylose maize starches are not equivalent producers of butyrate for the colonic mucosa. Br J Nutr 84, 689-696.

Mongeau R \& Brassard R (1982) Insoluble dietary fiber from breakfast cereals and brans: bile salt binding and water-holding capacity in relation to particle size. Cereal Chem 59, 413-417.

Owen RW (1997) Faecal steroids and colorectal carcinogenesis. Scand J Gastroenterol 32, Suppl. 222, 76-82.

Panfili G, Fratianni A \& Irano M (2003) Normal phase high-performance liquid chromatography method for the determination of tocopherols and tocotrienols in cereals. J Agric Food Chem 51, 3940-3944.

Peterson DM (2001) Oat antioxidants. J Cereal Sci 33, 115-129.

Prosky L, Asp N-G, Furda I, De Vries JW, Schweizer TF \& Harland F (1988) Determination of insoluble, soluble and total dietary fiber in foods and food products: interlaboratory study. J Assoc Off Anal Chem 71, 1017-1023.

Robertson JA, Majsak-Newman G \& Ring SG (1997) Release of mixed linkage $(1 \rightarrow 3),(1 \rightarrow 4) \beta$-D-glucans from barley by protease activity and effects on ileal effluents. Intern J Biol Macromol 21, 57-60.

Roy P, Owen RW, Faivre J, Scheppach W, Saldhana MH, Beckly DE, Bourtrou MC (1999) Faecal neutral sterols and bile acids in patients with adenomas and the large bowel cancer: an ECP case-control study. Eur J Cancer Prev 8, 409-515.

Schmehl K, Dongowski G, Nyska A \& Pfister C (1997) Einfluß von Pektin unterschiedlichen Veresterungsgrades auf die Darmschleimhaut von Ratten [Influence of pectin with different degree of esterification on the mucosa of rats]. Z Ernährungswiss 36, 34-35, (abstract).

Schmiedl D, Bäuerlein M, Bengs H \& Jacobasch G (2000) Production of heat-stable, butyrogenic resistant starch. Carbohydr Polym 43, $183-193$

Sembries S, Dongowski G, Jacobasch G, Mehrländer K, Will F \& Dietrich H (2003) Effects of DF-rich juice colloids from apple pomace extraction juices on intestinal fermentation products and microbiota in rats. Br J Nutr 90, 607-615.

Smith JG, Yokoyama WH \& German JB (1998) Butyric acid from the diet: actions at the level of gene expression. Crit Rev Food Sci 38, 259-297.

Spiller GA (2001) CRC Handbook of Dietary Fiber in Human Nutrition. Boca Raton, FL: CRC Press.

Sundberg B, Wood P, Lia A, Andersson H, Sandberg AS, Hallmanns G \& Aman P (1996) Mixed-liked $\beta$-glucan from breads of different cereals is partly degraded in the human ileostomy model. Am J Clin Nutr 64, $878-885$.

Tejinder S, Bhupinder K \& Harinder K (2000) Flow behavior and functional properties of barley and oat water-soluble $\beta$-D-glucan rich extractions. Int J Food Prop 3, 259-274.

Tierny Y, Béchet M, Joncquiert JC, Dubourguler HC \& Guillaume JB (1994) Molecular cloning and expression in Escherichia coli of genes encoding pectate lyase and pectin methylesterase activities from Bacteroides thetaiotaomicron. J Appl Microbiol 75, $592-602$. 
Topping DL \& Clifton PM (2001) Short-chain fatty acids and human colonic functions: roles of resistant starch and nonstarch polysaccharides. Physiol Rev 81, 1031-1064.

Van der Kamp JW, Asp NG, Miller Jones J \& Schaafsma G (2004) DF. Bio-active Carbohydrates for Food and Feed. Wageningen, The Netherlands: Wageningen Academic Publishers.

Van Munster IP, Tangerman A \& Nagengast FM (1994) Effect of resistant starch on colonic fermentation, bile acid metabolism and mucosal proliferation. Dig Dis Sci 39, 834-842.

Vårum KM, Martinsen A \& Smidsrød O (1991) Fractionation and viscometric characterisation of a $(1 \rightarrow 3),(1 \rightarrow 4)-\beta$-D-glucan from oat and using universal calibration of high-performance size chromatographic system by the use of fractionated $\beta$-glucans, alginates and pullulans. Food Hydrocoll 5, 363-374.

Velázquez OC, Seto RW, Bain AM, Fisher J \& Rombeau JL (1997) Desoxycholate inhibits in vivo butyrate-mediated BrDU labeling of the colonic crypt. J Surg Res 69, 344-348.

Wang WM \& Klopfenstein CF (1993) Effects of twin-screw extrusion on the nutritional quality of wheat, barley, and oats. Cereal Chem $\mathbf{7 0}$, $712-715$.
Westerlund E, Andersson R \& Åman P (1993) Isolation and chemical characterization of water-soluble mixed-linked $\beta$-glucans and arabinoxylans in oat milling fractions. Carbohydr Polym 20 , $115-123$.

Wood PJ, Arrigoni E, Miller S \& Amadò R (2002) Fermentability of oat and wheat fractions enriched in $\beta$-glucan using human fecal inoculum. Cereal Chem 79, 445-454.

Zadernowski R, Nowak-Polakowska H \& Rashed AA (1999) The influence of heat treatment on the activity of lipo- and hydrophilic components of oat grain. J Food Proc Preserv 23, 177-191.

Zhang D, Doehlert DC \& Moore WR (1998) Rheological properties of $(1 \rightarrow 3),(1 \rightarrow 4)-\beta$-D-glucans from raw, roasted, and steamed oat groats. Cereal Chem 75, 433-438.

Zhang J-X, Hallmans G, Andersson H, Bosaeus I, Åman P, Tidehag P, Stenling R, Lundin E \& Dahlgren S (1992) Effect of oat bran on plasma cholesterol and bile acids in nine subjects with ileostomies. Am J Clin Nutr 56, 99-105.

Zhang J-X, Hallmans G, Adlercreutz H, Åman P, Westerlund E, Lundin E \& Stenling R (1993) Effects of oat and rye fractions on biliary and fecal bileacid profiles in Syrian golden-hamsters. Br J Nutr 70, 525-536. 